University of Wollongong

Research Online

Faculty of Engineering and Information

Faculty of Engineering and Information

Sciences - Papers: Part B

Sciences

2020

\title{
Numerical simulations of circular high strength concrete-filled aluminum tubular short columns incorporating new concrete confinement model
}

Vipulkumar I. Patel

Victoria University, La Trobe University

Qing Quan Liang

Victoria University, qing.liang@vu.edu.au

Muhammad N. S Hadi

University of Wollongong, mhadi@uow.edu.au

Follow this and additional works at: https://ro.uow.edu.au/eispapers1

Part of the Engineering Commons, and the Science and Technology Studies Commons

Research Online is the open access institutional repository for the University of Wollongong. For further information contact the UOW Library: research-pubs@uow.edu.au 


\title{
Numerical simulations of circular high strength concrete-filled aluminum tubular short columns incorporating new concrete confinement model
}

\author{
Abstract \\ Concrete-filled aluminum tubular (CFAT) columns have the advantages of a lightweight, high resistance to \\ corrosion, good appearance and ease of maintenance over concrete-filled steel tubular (CFST) columns. \\ However, experimental and computational studies on the performance of CFAT columns have rarely been \\ reported. This paper concerns with the fiber-based numerical analysis, structural behavior, and design of \\ circular high strength CFAT stub columns loaded concentrically. A new concrete confinement model for \\ computing the lateral pressures on the concrete core in CFAT circular columns is proposed and \\ implemented in the computational model. The numerical analysis procedure is given for the \\ determination of the nonlinear load-strain behavior of CFAT stub columns. The available experimental \\ results of circular CFAT columns are used to assess the accuracy of the developed model. The computer \\ model is employed to ascertain the significance of various geometric parameters in addition to material \\ strengths on the responses of CFAT stub circular columns. The design equation based on Liang- \\ Fragomeni's expression is proposed for quantifying the ultimate axial strengths of axially compressed \\ CFAT short columns. The verification reveals that the computer modeling approach accurately quantifies \\ the ultimate loads and nonlinear load-strain performance of CFAT columns with circular sections. The \\ proposed design equation yields good calculations of the ultimate axial strengths of CFAT columns.

\section{Disciplines} \\ Engineering | Science and Technology Studies

\section{Publication Details} \\ Patel, V. Ishvarbhai., Liang, Q. \& Hadi, M. N. S. (2020). Numerical simulations of circular high strength \\ concrete-filled aluminum tubular short columns incorporating new concrete confinement model. Thin- \\ Walled Structures, 147 106492-1-106492-14.
}


Patel, V. I., Liang, Q. Q. and Hadi, M. N. S. (2020). Numerical simulations of circular high strength concrete-filled aluminum tubular short columns incorporating new concrete confinement model. Thin-Walled Structures, 147: 106492.

\title{
Numerical simulations of circular high strength concrete-filled aluminum tubular short columns incorporating new concrete confinement model
}

\author{
Vipulkumar Ishvarbhai Patel ${ }^{\mathrm{a}}$, Qing Quan Liang ${ }^{\mathrm{b}, 1}$, Muhammad N. S. Hadic \\ ${ }^{a}$ School of Engineering and Mathematical Sciences, La Trobe University, Bendigo, VIC 3552, \\ Australia \\ ${ }^{b}$ College of Engineering and Science, Victoria University, PO Box 14428, Melbourne, \\ VIC 8001, Australia \\ 'School of Civil, Mining and Environmental Engineering, University of Wollongong, \\ Wollongong, NSW 2522, Australia
}

\section{ABSTRACT}

Concrete-filled aluminum tubular (CFAT) columns have the advantages of a lightweight, high resistance to corrosion, good appearance and ease of maintenance over concrete-filled steel tubular (CFST) columns. However, experimental and computational studies on the performance of CFAT columns have rarely been reported. This paper concerns with the fiberbased numerical analysis, structural behavior, and design of circular high strength CFAT stub columns loaded concentrically. A new concrete confinement model for computing the lateral pressures on the concrete core in CFAT circular columns is proposed and implemented in the computational model. The numerical analysis procedure is given for the determination of the nonlinear load-strain behavior of CFAT stub columns. The available experimental results of circular CFAT columns are used to assess the accuracy of the developed model. The computer model is employed to ascertain the significance of various geometric parameters in addition to material strengths on the responses of CFAT stub circular columns. The design equation based

\footnotetext{
${ }^{1}$ Corresponding author.

E-mail address: Qing.Liang@,vu.edu.au (Q. Q. Liang)
} 
Patel, V. I., Liang, Q. Q. and Hadi, M. N. S. (2020). Numerical simulations of circular high strength concrete-filled aluminum tubular short columns incorporating new concrete confinement model. Thin-Walled Structures, 147: 106492.

on Liang-Fragomeni's expression is proposed for quantifying the ultimate axial strengths of axially compressed CFAT short columns. The verification reveals that the computer modeling approach accurately quantifies the ultimate loads and nonlinear load-strain performance of CFAT columns with circular sections. The proposed design equation yields good calculations of the ultimate axial strengths of CFAT columns.

Keywords Concrete-filled aluminum tubes; Composite columns; Aluminum contribution ratio; Fiber element modeling; Nonlinear analysis.

\section{Introduction}

Concrete-filled steel tubular (CFST) columns have high performance in terms of strength, earthquake resistance, ductility and stiffness, and are therefore often used in composite buildings [1]. Due to its lightweight and high corrosion resistance, aluminum has been widely used in the construction of high-rise buildings, such as the Empire State Building in New York, 30 St Mary Axe in London, and the Bank of China headquarters in Hong Kong. The weight of CFST columns could significantly be reduced by replacing the steel tubes with aluminum ones. Circular concrete-filled aluminum tubular (CFAT) columns as schematically shown in Fig. 1 have the advantages of a lightweight, high corrosion resistance, good appearance, and ease of maintenance in comparisons with CFST columns. However, the welding of aluminum requires a special process which limits the use of aluminum for the structural application. In addition, the cost of aluminum is two times higher than that of steel. As depicted in Fig. 2, the stressstrain response of aluminum significantly differs from that of structural steels. Unlike the mild steel, aluminum exhibits the rounded stress-strain curve without a well-defined yield strength. Therefore, the $0.2 \%$ proof stress is usually used to represent the aluminum yield strength. The 
Patel, V. I., Liang, Q. Q. and Hadi, M. N. S. (2020). Numerical simulations of circular high strength concrete-filled aluminum tubular short columns incorporating new concrete confinement model. Thin-Walled Structures, 147: 106492.

elastic modulus of aluminum material is remarkably lower than that of structural steel. Because of the material characteristics of aluminum, the structural behavior of CFAT columns is different from that of CFST columns. Therefore, to quantify the behavior of circular CFAT short columns, further computational studies are necessary and important.

Extensive studies have been performed to ascertain the responses of CFST columns fabricated by carbon and stainless steel tubes [2-8]. However, only a few experimental studies on square, rectangular and circular CFAT stub columns and double-skin concrete-filled aluminum tubular (DCFAT) columns of circular sections loaded concentrically were conducted by Zhou and Young [9-11]. The filled concrete had the compressive strengths of $40 \mathrm{MPa}, 70 \mathrm{MPa}$, and 100 $\mathrm{MPa}$, which were used to assess the influences of concrete strength on the nonlinear responses of short CFAT and DCFAT columns. For rectangular and square cross-sections, the depth-tothickness ratio ranged from 8.2 to 63.8 while the diameter-to-thickness $(D / t)$ ratio of circular sections varied from 9.7 to 59.2. The failure modes of CFAT columns with slender sections were the outward local buckling and splitting of aluminum tubes and crushing of concrete near the buckled regions. It was found that the initial stiffness of a CFAT column was higher than that of the corresponding hollow aluminum tubular column.

Computational models developed using the commercial finite element (FE) software Abaqus and the efficient fiber approach have been well established by a number of investigators for determining the structural responses of CFST columns to design actions [12-18]. The CFAT columns are relatively new composite columns, which have received very limited attention. Wang et al. [19] presented a numerical study on the behavior of concentrically loaded circular CFAT stub columns. They utilized the computer program Abaqus to create FE models to predict the behavior of CFAT stub columns loaded axially to failure. The measured stress- 
Patel, V. I., Liang, Q. Q. and Hadi, M. N. S. (2020). Numerical simulations of circular high strength concrete-filled aluminum tubular short columns incorporating new concrete confinement model. Thin-Walled Structures, 147: 106492.

strain response of aluminum material was directly adopted in the finite element analysis. Patel et al. [20] developed a computational model implementing the method of fiber analysis, which can predict the structural performance of concentrically compressed circular DCFAT stub columns. The modeling approach considered the double-skin confinement to capture the interaction effect of aluminum tubes and sandwiched concrete. The nonlinear stress-strain laws proposed by Abdella [21] based on Ramberg and Osgood equation [22] were employed to simulate the behavior of aluminum material. The computer modeling technique developed was shown to simulate well the structural behavior of DCFAT columns. The numerical results indicated that the use of aluminum tube instead of a steel one could approximately reduce the column weight by $22.5 \%$. It was also reported that the current design provisions for circular CFST columns either overestimated or underestimated the ultimate loads of circular DCFAT columns while Liang's design equation [23] produced accurate design strengths.

It has been found that only one numerical study has been undertaken on the performance of circular short CFAT columns [19]. To bridge this knowledge gap, this paper presents the numerical analysis, behavior, and design of concentrically compressed circular high strength CFAT stub columns incorporating a new confinement model. A computational model using the approach of fiber elements is proposed that calculates the load-strain responses of short circular CFAT columns loaded concentrically to failure. The verification of the fiber-based nonlinear simulation model is undertaken. The significance of geometric parameters in addition to material strengths on the nonlinear axial load-strain behavior, strain ductility index and aluminum contribution ratio is examined. The Liang-Fragomeni equation [13] proposed for circular CFST columns to the design of circular CFAT stub columns is assessed. 
Patel, V. I., Liang, Q. Q. and Hadi, M. N. S. (2020). Numerical simulations of circular high strength concrete-filled aluminum tubular short columns incorporating new concrete confinement model. Thin-Walled Structures, 147: 106492.

\section{Formulation of computational model}

\subsection{Basic theory}

The basic theory underlying the computational model is based on the method of fiber elements, which is employed to divide the column cross-section into fiber elements [1,24]. The analysis method has been proved to be accurate and computationally efficient for modeling the behavior of inelastic composite sections with the ability to handle gradual yielding and local buckling $[16,17]$. Liang's discretization technique [23] developed for a circular steel cross-section filled with concrete is employed herein. In this technique, the origin of the coordinate system is located at the section centroid. The aluminum tube wall is discretized into several circumferential layers $n_{a f}$ through its thickness. The number of layers $n_{a f}$ is specified by the user. The number of aluminum regions $n_{a r}$ is determined from the specified circumference layers $n_{a f}$ using the equation $n_{a r}=(\pi D) /\left(t / n_{a f}\right)$, where $D$ is the outer diameter of the tube and $t$ its thickness. The discretization of the cross-section results in circular sector elements as presented in Fig. 3.

The assumptions underlying the fiber model are summarized as: (a) there is no slippage between the concrete and aluminum tube; (b) concrete confinement is considered explicitly in the stress-strain laws of concrete; (c) the local buckling of circular CFAT columns is not considered as practical circular CFAT columns usually have a diameter-to-thickness ratio less than 150 for which local buckling would not occur before the ultimate load of the columns is attained [25]; (d) the failure occurs if the extreme compressive strain of concrete exceeds the prescribed ultimate strain; (e) the influence of concrete shrinkage as well as creep is neglected; (f) CFAT columns are exposed to room temperature. 
Patel, V. I., Liang, Q. Q. and Hadi, M. N. S. (2020). Numerical simulations of circular high strength concrete-filled aluminum tubular short columns incorporating new concrete confinement model. Thin-Walled Structures, 147: 106492.

In the method of fiber analysis, each element represents either a steel fiber or a concrete fiber and can be given the material properties of either steel or concrete. The longitudinal stresses are computed from axial strains by means of applying the uniaxial material constitutive laws. The internal axial force $(P)$ in the cross-section is determined by integrating the fiber stresses over the entire cross-section as

$$
P=\sum_{i=1}^{n a} A_{a, i} \sigma_{a, i}+\sum_{j=1}^{n c} A_{c, j} \sigma_{c, j}
$$

in which $n a, n c$ are the numbers of aluminum and concrete elements, respectively; $A_{a, i}, A_{c, j}$ the elemental areas of aluminum and concrete fibers, respectively; and $\sigma_{a, i}, \sigma_{c, j}$ the elemental stresses of aluminum and concrete fibers, respectively.

\subsection{Computer simulation procedure}

The analysis of a circular CFAT column firstly discretizes the cross-section into small fiber elements. The area and coordinates of each fiber element are then computed. After that, the axial strain is increased incrementally from zero to the prescribed ultimate concrete strain. Since the force-control method, in which the axial force increases from zero to the ultimate load, cannot capture the post-peak behavior of circular CFAT columns, the strain-control technique is employed in the present study. For each strain increment, the stress in each fiber is computed by using the nonlinear stress-strain relations of aluminum and concrete, which are given in Section 3. The above computation process is repeated until the axial load-strain responses of CFAT circular columns are completely determined. The computer flowchart that 
Patel, V. I., Liang, Q. Q. and Hadi, M. N. S. (2020). Numerical simulations of circular high strength concrete-filled aluminum tubular short columns incorporating new concrete confinement model. Thin-Walled Structures, 147: 106492.

models the load-axial strain responses of CFAT columns is demonstrated in Fig. 4, where $P_{\max }$ is the ultimate axial strength of a CFAT column.

\subsection{Contribution ratios of aluminum tube and concrete}

The contribution ratio can be used to study the economic design of circular CFAT short columns [26]. The aluminum and concrete contributions to the ultimate axial strength of a circular CFAT short column are evaluated by the contribution ratios. Liang [26] proposed the equations for computing the contribution ratios as follows:

$$
\begin{aligned}
R_{a} & =\frac{P_{u . a}}{P_{u}} \\
R_{c} & =\frac{P_{u . c}}{P_{u}}
\end{aligned}
$$

in which $R_{a}$ and $R_{c}$ represent the aluminum and concrete contribution ratios, respectively; $P_{u . a}$ and $P_{u . c}$ denote the axial load of aluminum tube and concrete at the strain where CFAT column attains the ultimate axial strength, respectively; and $P_{u}$ stands for the ultimate axial load a circular CFAT short column.

\section{Material constitutive laws}

\subsection{Stress-strain relation of aluminum}

Ramberg and Osgood [22] developed an equation that describes the stress-strain relationship 
Patel, V. I., Liang, Q. Q. and Hadi, M. N. S. (2020). Numerical simulations of circular high strength concrete-filled aluminum tubular short columns incorporating new concrete confinement model. Thin-Walled Structures, 147: 106492.

of aluminum as a function of three parameters, including the $0.2 \%$ proof stress $\sigma_{0.2}$, Young's modulus $E_{0}$, and nonlinearity index $n$. The Ramberg-Osgood equation [22] expresses the strain as a function of stress. The strain-control procedure given in Section 2.2 requires the calculation of stresses using given strains [27]. Abdella [21] mathematically inverted the stressstrain equation proposed by Ramberg and Osgood [22] for aluminum. The inversion allows the stress to be computed directly from the strain. The stress-strain model given by Abdella [21] is implemented in the proposed computational model, and it is divided into two stages based on the strain range as shown in Fig. 5. In the first stage, the stress is calculated from strain by

$$
\begin{aligned}
& \sigma_{a}=\frac{\sigma_{0.2} r\left(\varepsilon_{a} / \varepsilon_{0.2}\right)}{1+(r-1)\left(\varepsilon_{a} / \varepsilon_{0.2}\right)^{p}} \quad \text { for } 0 \leq \varepsilon_{a} \leq \varepsilon_{0.2} \\
& r=\frac{E_{0} \varepsilon_{0.2}}{\sigma_{0.2}} \\
& p=\frac{r\left(1-r_{2}\right)}{r-1} \\
& r_{2}=\frac{E_{0.2} \varepsilon_{0.2}}{\sigma_{0.2}}
\end{aligned}
$$

in which $\varepsilon_{a}$ denotes the aluminum strain, $\sigma_{a}$ the stress at the strain $\varepsilon_{a}, E_{0}$ the Young's modulus of aluminum, $\sigma_{0.2}$ the $0.2 \%$ proof stress of aluminum, and $\varepsilon_{0.2}$ the strain at the stress $\sigma_{0.2}$, which is defined as [22]

$$
\varepsilon_{0.2}=0.002+\frac{\sigma_{0.2}}{E_{0}}
$$


Patel, V. I., Liang, Q. Q. and Hadi, M. N. S. (2020). Numerical simulations of circular high strength concrete-filled aluminum tubular short columns incorporating new concrete confinement model. Thin-Walled Structures, 147: 106492.

In Eq. (7), $E_{0.2}$ stands for the tangent modulus of aluminum, which is computed by [22]

$$
E_{0.2}=\frac{E_{0}}{1+0.002\left(n E_{0} / \sigma_{0.2}\right)}
$$

In the second stage, the aluminum stress is determined using the expressions proposed by Abdella [21] as

$$
\begin{aligned}
& \sigma_{a}=\sigma_{0.2}\left[1+\frac{r_{2}\left(\varepsilon_{a} / \varepsilon_{0.2}-1\right)}{1+\left(r^{*}-1\right)\left(\frac{\varepsilon_{a} / \varepsilon_{0.2}-1}{\varepsilon_{a u} / \varepsilon_{0.2}-1}\right)^{p^{*}}}\right] \quad \text { for } \varepsilon_{0.2}<\varepsilon_{a} \leq \varepsilon_{a u} \\
& r^{*}=\frac{E_{0.2}\left(\varepsilon_{a u}-\varepsilon_{0.2}\right)}{\left(\sigma_{a u}-\sigma_{0.2}\right)} \\
& p^{*}=\frac{r^{*}\left(1-r_{u}\right)}{r^{*}-1} \\
& r_{u}=\frac{E_{u}\left(\varepsilon_{a u}-\varepsilon_{0.2}\right)}{\sigma_{a u}-\sigma_{0.2}}
\end{aligned}
$$

The slope $E_{u}$ was proposed by Abdella [21] as

$$
E_{u}=\frac{E_{0.2}}{1+\left(r^{*}-1\right) m}
$$

where $m$ is the strain hardening parameter which was proposed by Rasmussen [28] as 
Patel, V. I., Liang, Q. Q. and Hadi, M. N. S. (2020). Numerical simulations of circular high strength concrete-filled aluminum tubular short columns incorporating new concrete confinement model. Thin-Walled Structures, 147: 106492.

$$
m=1+3.5 \frac{\sigma_{0.2}}{\sigma_{a u}}
$$

where $\sigma_{a u}$ denotes the ultimate stress of aluminum, which was obtained from the tension coupon test conducted by Zhou and Young [10]. In Fig. 5, $\varepsilon_{a u}$ is the strain at the stress $\sigma_{a u}$.

\subsection{Stress-strain relation of confined concrete}

The lateral expansion of concrete in a circular CFAT column is restrained by the aluminum tube under increasing axial compression. It has been well established that the circular tube effectively confines the concrete in a CFST column with a circular section so that both the ductility and compressive strength of the filled concrete improve. The nonlinear stress-strain relationship depicted in Fig. 6 suggested by Liang and Fragomeni [13] is implemented in the computational model proposed to simulate the nonlinear response of confined concrete in CFAT columns of circular sections. The equation given by Mander et al. [29] is used to express the branch OA as

$$
\sigma_{c}=\frac{f_{c c}^{\prime} \lambda\left(\varepsilon_{c} / \varepsilon_{c c}^{\prime}\right)}{\lambda-1+\left(\varepsilon_{c} / \varepsilon_{c c}^{\prime}\right)^{\lambda}} \quad \text { for } 0 \leq \varepsilon_{c} \leq \varepsilon_{c c}^{\prime}
$$

where $\sigma_{c}$ stands for the concrete stress in compression, $\varepsilon_{c}$ the strain at stress $\sigma_{c}, f_{c c}^{\prime}$ and $\varepsilon_{c c}^{\prime}$ the axial compressive strength and strain of the confined concrete respectively, and $\lambda$ is expressed by 
Patel, V. I., Liang, Q. Q. and Hadi, M. N. S. (2020). Numerical simulations of circular high strength concrete-filled aluminum tubular short columns incorporating new concrete confinement model. Thin-Walled Structures, 147: 106492.

$$
\lambda=\frac{E_{c}}{E_{c}-\left(f_{c c}^{\prime} / \varepsilon_{c c}^{\prime}\right)}
$$

where $E_{c}$ stands for the concrete elastic modulus, which is determined as [30]

$$
E_{c}=3320 \sqrt{\gamma_{c} f_{c}^{\prime}}+6900(\mathrm{MPa})
$$

where $f_{c}^{\prime}$ is the axial compressive strength of filled concrete, and $\gamma_{c}$ the concrete strength reduction parameter derived by Liang [24] to consider the scale effect, given by

$$
\gamma_{c}=1.85 D_{c}^{-0.135} \quad\left(0.85 \leq \gamma_{c} \leq 1.0\right)
$$

where $D_{c}$ is the concrete diameter shown in Fig. 1 and the unit for $D_{c}$ is mm.

The linear branches $\mathrm{AB}$ and $\mathrm{BC}$ shown in Fig. 6 are simulated using the following equations:

$$
\sigma_{c}= \begin{cases}\beta_{c c} f_{c c}^{\prime}+\left(f_{c c}^{\prime}-\beta_{c c} f_{c c}^{\prime}\right)\left(\frac{\varepsilon_{c}-0.02}{\varepsilon_{c c}^{\prime}-0.02}\right) & \text { for } \varepsilon_{c c}^{\prime}<\varepsilon_{c} \leq 0.02 \\ \beta_{c c} f_{c c}^{\prime} & \text { for } \varepsilon_{c}>0.02\end{cases}
$$

in which $\beta_{c c}$ represents the strength degradation parameter. The following expressions presented by $\mathrm{Hu}$ et al. [12] are used to determine $\beta_{c c}$ : 
Patel, V. I., Liang, Q. Q. and Hadi, M. N. S. (2020). Numerical simulations of circular high strength concrete-filled aluminum tubular short columns incorporating new concrete confinement model. Thin-Walled Structures, 147: 106492.

$$
\beta_{c c}= \begin{cases}1.0 & \text { for } 22 \leq \frac{D}{t} \leq 40 \\ 1.3491+0.0000339\left(\frac{D}{t}\right)^{2}-0.010085\left(\frac{D}{t}\right) & \text { for } 40<\frac{D}{t} \leq 150\end{cases}
$$

It would appear from Eq. (21) that for small $D / t$ ratios varying from 22 to 40 , the aluminum tube offers strong confinement to the concrete so that its strength does not degrade. However, for the $D / t$ ratio greater than 40 , the aluminum tube provides less confinement to the concrete that exhibits softening behavior as depicted in Fig. 6 .

\subsection{Proposed concrete confinement model}

The compressive strength $\left(f_{c c}^{\prime}\right)$ and its corresponding strain $\left(\varepsilon_{c c}^{\prime}\right)$ of confined concrete are determined by employing the equations given by Mander et al. [29] with the factor $\gamma_{c}$ proposed by Liang [24] to account for the scale effect. The equations are expressed by

$$
\begin{aligned}
& f_{c c}^{\prime}=\gamma_{c} f_{c}^{\prime}+4.1 f_{r p} \\
& \varepsilon_{c c}^{\prime}=\varepsilon_{c}^{\prime}\left(1+20.5 \frac{f_{r p}}{\gamma_{c} f_{c}^{\prime}}\right)
\end{aligned}
$$

where $f_{r p}$ represents the lateral pressure on the concrete, and $\varepsilon_{c}^{\prime}$ the strain at stress $f_{c}^{\prime}$, which can be determined by the expressions suggested by Liang [24] as 
Patel, V. I., Liang, Q. Q. and Hadi, M. N. S. (2020). Numerical simulations of circular high strength concrete-filled aluminum tubular short columns incorporating new concrete confinement model. Thin-Walled Structures, 147: 106492.

$$
\varepsilon_{c}^{\prime}= \begin{cases}0.002 & \text { for } \gamma_{c} f_{c}^{\prime} \leq 28 \mathrm{MPa} \\ 0.002+\frac{\gamma_{c} f_{c}^{\prime}-28}{54000} & \text { for } 28<\gamma_{c} f_{c}^{\prime} \leq 82 \mathrm{MPa} \\ 0.003 & \text { for } \gamma_{c} f_{c}^{\prime}>82 \mathrm{MPa}\end{cases}
$$

The Young's modulus of aluminum is $70 \mathrm{GPa}$, which is significantly lower than that of steel with $200 \mathrm{GPa}$. Therefore, the lateral confining pressure exerted by the aluminum tube is different from that offered by the carbon steel tube. It is important to develop a new confinement model for quantifying the lateral pressures on the concrete in circular CFAT columns to accurately determine $f_{c c}^{\prime}$ and $\varepsilon_{c c}^{\prime}$. The lateral confining pressure on the concrete in a circular CFAT column depends on the diameter-to-thickness $D / t$ ratio and $0.2 \%$ proof strength $\sigma_{0.2}$ of the aluminum tube. The regression analysis based on the multiple polynomial method was used to fit a surface to the experimental lateral confining pressures. Figure 7 depicts the surface fitting based on the experimental results [10]. A new concrete confinement model for predicting the lateral pressure $f_{r p}$ on the concrete confined by circular aluminum tubes is proposed herein as

$$
\begin{aligned}
f_{r p}= & 0.00249\left(\frac{D}{t}\right) \sigma_{0.2}-0.002297\left(\frac{D}{t}\right)^{2}+0.001269 \sigma_{0.2}^{2} \\
& -0.5329\left(\frac{D}{t}\right)-0.7214 \sigma_{0.2}+104.24
\end{aligned}
$$

The proposed confinement model has been implemented in the constitutive laws for confined concrete, which have been found to simulate well the ultimate strengths of CFAT columns as demonstrated in Section 4. The comparison of lateral pressures on concrete confined by the aluminum and carbon steel tubes are given in Section 5.1. The lateral confining pressure 
Patel, V. I., Liang, Q. Q. and Hadi, M. N. S. (2020). Numerical simulations of circular high strength concrete-filled aluminum tubular short columns incorporating new concrete confinement model. Thin-Walled Structures, 147: 106492.

induced by the steel tube to the concrete core in a CFST column can be determined using the equation proposed by Liang and Fragomeni [13].

\section{Comparisons of computations against test data}

\subsection{Ultimate loads}

Experimental results given by Zhou and Young [10] on concentrically compressed circular CFAT short columns were used to verify the developed numerical model. Table 1 provides the dimensions of tested columns and material strengths of aluminum and concrete. The nonlinearity index $(n)$ for aluminum was not given by Zhou and Young [10] and was taken as 5.0 for the verification of the model. The diameter-to-thickness $(D / t)$ ratios of the tested specimens varied from 9.7 to 59.2. Equation (21) applies to $D / t$ ratios ranging from 22 to 150 . For the analysis of the tested specimens with a $D / t$ ratio less than 22 , the factor $\beta_{c c}$ was taken as 1.0. In Table 1, $P_{u \text {.exp }}$ stands for the experimental ultimate load, and $P_{u . n u m}$ represents the numerical ultimate load. The mean, standard deviation (SD), and coefficient of variation $(\mathrm{COV})$ of the $P_{u . n u m} / P_{\text {u.exp }}$ ratios are $0.996,0.056$ and 0.056 , respectively. The statistical analysis confirms that the computer model accurately quantifies the ultimate loads of CFAT short circular columns loaded axially.

\subsection{Axial load-strain responses}

The numerically computed load-strain responses of concentrically loaded CFAT short columns of circular sections are compared against test data given by Zhou and Young [10]. Figure 8 
Patel, V. I., Liang, Q. Q. and Hadi, M. N. S. (2020). Numerical simulations of circular high strength concrete-filled aluminum tubular short columns incorporating new concrete confinement model. Thin-Walled Structures, 147: 106492.

provides the experimental and numerical load-strain responses of Specimens CHS2C40, CHS2C70, CHS7C40, and CHS7C70. As can be found from Fig. 8, the computer model accurately captures the initial stiffness, ultimate loads and post-peak responses of the tested columns except Specimen CHS7C70. This discrepancy is mainly induced by the uncertainty of the actual concrete compressive strength of the tested columns. The comparison reveals that the computational model accurately ascertains the nonlinear load-axial strain behavior of concentrically compressed short CFAT columns.

\section{Behavior of circular CFAT short columns}

The numerical technique developed was utilized to examine the influences of aluminum and concrete strengths, and geometric properties on the ultimate axial loads, performance indices, and load-strain responses of circular CFAT columns. The Young's modulus $\left(E_{0}\right)$ and nonlinearity index $(n)$ of aluminum were taken as $69 \mathrm{GPa}$ and 5.0, respectively. The ultimate strain of concrete $\left(\varepsilon_{c u}\right)$ was specified as 0.04 in the numerical analyses. The axial strength and strain ductility of CFAT columns were evaluated using the performance indices in term of strain ductility [13]. The strain ductility index $\left(P I_{a c}\right)$ of a CFAT column was determined by $P I_{s d}=\varepsilon_{u .90} / \varepsilon_{y .75}$, where $\varepsilon_{y .75}$ was equal to $\varepsilon_{0.75} / 0.75$ and $\varepsilon_{0.75}$ was the strain at $0.75 P_{u}$ in the ascending load-strain branch [13]. For columns exhibiting strain-softening behavior, the strain $\varepsilon_{u .90}$ was taken as the strain at $0.90 P_{u}$. For columns displaying strain hardening behavior, the strain $\varepsilon_{u .90}$ was specified as the ultimate concrete strain $\varepsilon_{c u}$ [13]. The range of parameters is selected for reflecting the use of CFAT columns in high-rise buildings. 
Patel, V. I., Liang, Q. Q. and Hadi, M. N. S. (2020). Numerical simulations of circular high strength concrete-filled aluminum tubular short columns incorporating new concrete confinement model. Thin-Walled Structures, 147: 106492.

\subsection{Comparison of confining pressures by steel and aluminum tubes}

The lateral confining pressures exerted by the carbon steel tube of a circular CFST column were predicted using the concrete confinement model developed by $\mathrm{Hu}$ et al. [12] and Tang et al. [31]. The concrete confinement induced by the aluminum tube in a circular CFAT column was determined by the proposed Eq. (25) of this paper. The comparison of the confining pressures by the aluminum and carbon steel tubes is given in Table 2. As shown, the lateral pressure provided by the aluminum tube is lower than that exerted by the carbon steel tube. This is because the Young's modulus of aluminum is three times lower than that of carbon steel. It should be noted that Tang et al. [31] model might give negative confining pressures on the concrete in CFST columns with for small $D / t$ ratios.

\subsection{Load distributions in CFAT columns}

The load distribution analysis was conducted to quantify the contribution of aluminum tube and concrete to the fundamental performance of circular CFAT short columns. Columns C1$\mathrm{C} 4$ given in Table 3 were analyzed to study the effects of diameter-to-thickness $D / t$ ratio on the axial load distributions in circular CFAT columns. Figure 9 depicts the axial load-strain curves of aluminum tubes and concrete of circular CFAT columns with various $D / t$ ratios. It appears that the concrete carries a large amount of the axial load regardless of the $D / t$ ratio. The aluminum and concrete contributions as a function of the $D / t$ ratio are shown in Fig. 10 . It can be noted that the increase of the $D / t$ ratio generally decreases the contribution of aluminum tube to the ultimate axial load of circular CFAT columns. However, the concrete 
Patel, V. I., Liang, Q. Q. and Hadi, M. N. S. (2020). Numerical simulations of circular high strength concrete-filled aluminum tubular short columns incorporating new concrete confinement model. Thin-Walled Structures, 147: 106492.

contribution increases as the ratio of $D / t$ increases. It can be concluded that the CFAT column with a large $D / t$ ratio is economical.

Columns C5-8 given in Table 3 were numerically studied to examine the influence of aluminum proof strength on the aluminum tube and concrete load distribution in circular CFAT columns. Figure 11 illustrates the axial load-strain responses of aluminum tube and concrete in circular CFAT columns with various $0.2 \%$ proof strengths. The same trend is observed for the effect of aluminum proof strength on the concrete contribution in carrying the axial load. However, the aluminum contribution to the ultimate axial strength of circular CFAT columns slightly increases with increasing the aluminum proof strength as demonstrated in Fig. 12. With the $270 \mathrm{MPa}$ proof strength, the concrete and aluminum contribution ratios are 0.72 and 0.28 , respectively. It indicates that the CFAT columns should be made from the aluminum tubes with a high proof strength.

The developed model was utilized to simulate Columns C9-C12 provided in Table 3 for evaluating the effect of concrete strength on the load distribution of the concrete and aluminum in CFAT columns. The axial load-strain curves of aluminum tube and concrete for various concrete strengths are presented in Fig. 13. It demonstrates that the concrete contribution is higher than the aluminum tube in carrying the axial load. The concrete and aluminum contribution ratios as a function of concrete compressive strength are depicted in Fig. 14. It is interesting to note that the concrete contribution increases significantly with increasing the concrete strengths. With $100 \mathrm{MPa}$ concrete, the concrete contribution ratio is 0.84 compared to 0.16 for aluminum contribution ratio.

\subsection{Influence of diameter-to-thickness ratio}


Patel, V. I., Liang, Q. Q. and Hadi, M. N. S. (2020). Numerical simulations of circular high strength concrete-filled aluminum tubular short columns incorporating new concrete confinement model. Thin-Walled Structures, 147: 106492.

Inelastic analyses on Columns C1-C4 listed in Table 3 were undertaken by using the developed fiber model to assess the influence of $D / t$ ratio on the performance of CFAT columns. The various $D / t$ ratios for the same tube diameter were calculated by altering the thickness. The computed load-strain curves of these columns are provided in Fig. 15. It appears that the $D / t$ ratio has a minor influence on the initial stiffness of short CFAT columns. Nevertheless, it has a considerable influence on the column ultimate strength. The ultimate strength decreases when increasing the $D / t$ ratio or the tube thickness. As the $D / t$ ratio is changed from 60 to 70,80 and 100 , the reductions in the column ultimate strength are found to be $10 \%, 12 \%$ and $16 \%$, respectively. The strain ductility indices $P I_{s d}$ have been plotted against the $D / t$ ratios ranging from 60 to 100 in Fig. 16. The significant reduction in the ductility index is found when increasing the $D / t$ ratio from 60 to 70 . As the $D / t$ ratio increases from 70 to 100 , the ductility reduction is less. This is because the CFAT column with a large $D / t$ ratio exhibits more significant strain-softening behavior.

\subsection{Influence of aluminum proof stress}

The sensitivities of the initial stiffness, ductility index and ultimate axial load of CFAT columns to the aluminum proof stress were examined. The proof stresses ranging from $220 \mathrm{MPa}$ to 270 MPa were considered. The fiber-based model was employed to simulate Columns C5-C8 listed in Table 3. Figure 17 demonstrates the comparison of the load-strain responses of CFAT columns with $220 \mathrm{MPa}$ and $270 \mathrm{MPa}$ aluminum proof stress. As appeared from the figure, the ultimate load of the CFAT column with the proof stress of $270 \mathrm{MPa}$ is $13 \%$ higher than that of the one with proof stress of $220 \mathrm{MPa}$. Figure 18 presents the strain ductility-aluminum proof stress responses. It is demonstrated that the strain ductility index $P I_{s d}$ decreases with an 
Patel, V. I., Liang, Q. Q. and Hadi, M. N. S. (2020). Numerical simulations of circular high strength concrete-filled aluminum tubular short columns incorporating new concrete confinement model. Thin-Walled Structures, 147: 106492.

increase in the proof stress. The index $P I_{s d}$ is reduced from 14.9 to 12.3 by increasing $\sigma_{0.2}$ from $220 \mathrm{MPa}$ to $270 \mathrm{MPa}$.

\subsection{Influence of concrete strength}

The structural behavior of Columns C9-C12 listed in Table 3 was simulated using the numerical model to assess the significance of concrete compressive strength on their behavior. The nonlinear structural responses of short CFAT columns with different concrete strengths to axial compression are provided in Fig. 19. Increasing the concrete strength is shown to slightly improve the column initial stiffness, but remarkably increases the ultimate strengths of CFAT columns. For instance, the ultimate strengths are increased by $41 \%, 66 \%$ and $99 \%$, respectively, by changing the concrete strength from $40 \mathrm{MPa}$ to $65 \mathrm{MPa}, 80 \mathrm{MPa}$ and $100 \mathrm{MPa}$. It reveals that high-strength concrete can be used in CFAT columns to improve their strength performance. As illustrated in Fig. 20, the strain ductility index $P I_{s d}$ is shown to decrease as the higher strength concrete is used, which is caused by the brittle behavior of high-strength concrete. The strain ductility indices were obtained as 19.3, 18.1, 16.9 and 15.7 for CFAT columns with concrete strengths of $40 \mathrm{MPa}, 65 \mathrm{MPa}, 80 \mathrm{MPa}$, and $100 \mathrm{MPa}$, respectively.

\subsection{Comparison of CFST and CFAT columns}

The computer simulation method proposed was used to ascertain the responses of short circular CFAT and CFST columns to axial loads. The same dimensions and material strengths of Column C13 listed in Table 3 were used in the computer simulations. The fiber-based computer program written by Liang [23] was employed to compute the load-strain response of the circular CFST column. The simulated load-strain curves for CFST and CFAT columns have 
Patel, V. I., Liang, Q. Q. and Hadi, M. N. S. (2020). Numerical simulations of circular high strength concrete-filled aluminum tubular short columns incorporating new concrete confinement model. Thin-Walled Structures, 147: 106492.

been plotted in Fig. 21. It is interesting to note that the CFAT column has slightly lower ultimate strength and initial stiffness than the CFST column. This is because aluminum has a lower elastic modulus and rounded stress-strain curve. However, both columns exhibit similar post-yield responses.

\section{Design of circular CFAT short columns}

Liang and Fragomeni [13] developed a formula for the design of concentrically compressed circular short CFST columns including concrete confinement effects. The design equation of Liang and Fragomeni [13] is modified herein by means of replacing the steel yield stress $f_{y}$ with the aluminum proof stress $\sigma_{0.2}$ and the factor $\gamma_{a}$ for aluminum tube as follows:

$$
P_{\text {ucal }}=\left(\gamma_{c} f_{c}^{\prime}+4.1 f_{r p}\right) A_{c}+\gamma_{a} \sigma_{0.2} A_{a}
$$

in which $\gamma_{c}$ is determined using Eq. (19), $f_{r p}$ is calculated using Eq. (25) and the factor $\gamma_{a}$ is used to consider the effects of $D / t$ ratio and strain-hardening and is proposed herein as

$\gamma_{a}=1.725\left(\frac{D}{t}\right)^{-0.192}$

The ultimate axial loads of short circular CFAT columns determined by the modified equation of Liang and Fragomeni [13] are compared against the available test data in Table 4. It is indicated that the ultimate axial loads computed using the modified equations Eqs. (26) and (27) are in good agreement with experimental data, leading to a mean calculated-to-test ratio 
Patel, V. I., Liang, Q. Q. and Hadi, M. N. S. (2020). Numerical simulations of circular high strength concrete-filled aluminum tubular short columns incorporating new concrete confinement model. Thin-Walled Structures, 147: 106492.

of 0.993 , an SD of 0.061 , and a COV of 0.061 . This indicates that the modified design equations provide better strength predictions than codified design methods.

\section{Conclusions}

The fiber-based computer simulation model has been presented in this paper, which can predict the structural responses of short high strength CFAT columns with circular sections to concentric loads. The computational model incorporates not only the accurate stress-strain laws for aluminum but also the newly developed concrete confinement model for concrete confined by a circular aluminum tube. The basic theory underlying the computational model and the simulation procedure have been described for accurately capturing the axial load-strain performance of CFAT circular short columns. The concluding remarks are given as follows:

(1) The numerical model using the method of fiber analysis accurately simulates the behavior of circular short CFAT columns loaded concentrically to failure.

(2) The circular CFAT column has slightly lower initial stiffness than the equivalent circular CFST column because of the low elastic modulus of aluminum.

(3) Increasing the $D / t$ ratio markedly decreases the axial strength and strain ductility of CFAT columns.

(4) The ultimate load of CFAT columns is demonstrated to considerably increase by using aluminum tubes with higher proof stress.

(5) The use of high strength concrete remarkably increases the ultimate axial strength of CFAT columns but reduces the strain ductility and aluminum contribution ratio.

(6) The modified design model of Liang and Fragomeni [13] yields accurate strength calculations. 
Patel, V. I., Liang, Q. Q. and Hadi, M. N. S. (2020). Numerical simulations of circular high strength concrete-filled aluminum tubular short columns incorporating new concrete confinement model. Thin-Walled Structures, 147: 106492.

\section{References}

[1] Q.Q. Liang, Analysis and design of steel and composite structures, Boca Raton and London: CRC Press, Taylor and Francis Group, 2014.

[2] G. Giakoumelis, D. Lam, Axial capacity of circular concrete-filled tube columns, J. Constr. Steel Res. 60 (7) (2004) 1049-1068.

[3] K. Sakino, H. Nakahara, S. Morino, I. Nishiyama, Behavior of centrally loaded concretefilled steel-tube short columns, J. Struct. Eng. 130 (2) (2004) 180-188.

[4] B. Uy, Z. Tao, L.H. Han, Behaviour of short and slender concrete-filled stainless steel tubular columns, J. Constr. Steel Res. 67 (3) (2011) 360-378.

[5] J.Y.R. Liew, M. Xiong, D. Xiong, Design of Concrete Filled Tubular Beam-columns with High Strength Steel and Concrete, Structures. 8 (2) (2016) 213-226.

[6] L.H. Han, C.Y. Xu, Z. Tao, Performance of concrete filled stainless steel tubular (CFSST) columns and joints: Summary of recent research, J. Constr. Steel Res. 152 (2019) 117-131.

[7] Z. Huang, D. Li, B. Uy, H.T. Thai, C. Hou, Local and post-local buckling of fabricated high-strength steel and composite columns, J. Constr. Steel Res. 154 (2019) 235-249.

[8] F. Zhou, B. Young, Experimental investigation of concrete-filled single-skin and double-skin steel oval hollow section stub columns, Thin-Walled Struct. 140 (2019) $157-167$.

[9] F. Zhou, B. Young, Tests of concrete-filled aluminum stub columns, Thin-Walled Struct. 46 (6) (2008) 573-583.

[10] F. Zhou, B. Young, Concrete-filled aluminum circular hollow section column tests, Thin-Walled Struct. 47 (11) (2009) 1272-1280.

[11] F. Zhou, B. Young, Concrete-filled double-skin aluminum circular hollow section stub 
Patel, V. I., Liang, Q. Q. and Hadi, M. N. S. (2020). Numerical simulations of circular high strength concrete-filled aluminum tubular short columns incorporating new concrete confinement model. Thin-Walled Structures, 147: 106492.

columns, Thin-Walled Struct. 133 (2018) 141-152.

[12] H.-T. Hu, C.-S. Huang, M.-H. Wu, Y.-M. Wu, Nonlinear analysis of axially loaded concrete-filled tube columns with confinement effect, J. Struct. Eng. 129 (10) (2003) $1322-1329$.

[13] Q.Q. Liang, S. Fragomeni, Nonlinear analysis of circular concrete-filled steel tubular short columns under axial loading, J. Constr. Steel Res. 65 (12) (2009) 2186-2196.

[14] Z. Tao, Z. Bin Wang, Q. Yu, Finite element modelling of concrete-filled steel stub columns under axial compression, J. Constr. Steel Res. 89 (2013) 121-131.

[15] Z. Bin Wang, Z. Tao, L.H. Han, B. Uy, D. Lam, W.H. Kang, Strength, stiffness and ductility of concrete-filled steel columns under axial compression, Eng. Struct. 135 (2017) 209-221.

[16] M. Ahmed, Q.Q. Liang, V.I. Patel, M.N.S. Hadi, Nonlinear analysis of rectangular concrete-filled double steel tubular short columns incorporating local buckling, Eng. Struct. 175 (2018) 13-26.

[17] V.I. Patel, Q.Q. Liang, M.N.S. Hadi, Concrete-filled stainless steel tubular columns, Boca Raton and London: CRC Press, Taylor and Francis, 2018.

[18] V.I. Patel, M.F. Hassanein, H.T. Thai, H. Al Abadi, M. Elchalakani, Y. Bai, Ultra-high strength circular short CFST columns: Axisymmetric analysis, behaviour and design, Eng. Struct. 179 (2019) 268-283.

[19] F.C. Wang, H.Y. Zhao, L.H. Han, Analytical behavior of concrete-filled aluminum tubular stub columns under axial compression, Thin-Walled Struct. 140 (2019) 21-30.

[20] V.I. Patel, Q.Q. Liang, M.N.S. Hadi, Numerical study of circular double-skin concretefilled aluminum tubular stub columns, Eng. Struct. 197 (2019) 109418.

[21] K. Abdella, Inversion of a full-range stress-strain relation for stainless steel alloys, Int. J. Non. Linear. Mech. 41 (3) (2006) 456-463. 
Patel, V. I., Liang, Q. Q. and Hadi, M. N. S. (2020). Numerical simulations of circular high strength concrete-filled aluminum tubular short columns incorporating new concrete confinement model. Thin-Walled Structures, 147: 106492.

[22] W. Ramberg, W.R. Osgood, Description of stress-strain curves by three parameters, NACA Tech. Note No. 902. (1943).

[23] Q.Q. Liang, Nonlinear analysis of circular double-skin concrete-filled steel tubular columns under axial compression, Eng. Struct. 131 (2017) 639-650.

[24] Q.Q. Liang, Performance-based analysis of concrete-filled steel tubular beam-columns, Part I: Theory and algorithms, J. Constr. Steel Res. 65 (2009) 363-372.

[25] M.A. Bradford, H.Y. Loh, B. Uy, Slenderness limits for filled circular steel tubes, J. Constr. Steel Res. 58(2) (2002) 243-252.

[26] Q.Q. Liang, Numerical simulation of high strength circular double-skin concrete-filled steel tubular slender columns, Eng. Struct. 168 (2018) 205-217.

[27] V.I. Patel, Q.Q. Liang, M.N.S. Hadi, Nonlinear analysis of axially loaded circular concrete-filled stainless steel tubular short columns, J. Constr. Steel Res. 101 (2014) 918.

[28] K.J.R. Rasmussen, Full-range stress-strain curves for stainless steel alloys, J. Constr. Steel Res. 59 (1) (2003) 47-61.

[29] J.B. Mander, M.J.N. Priestley, R. Park, Theoretical stress strain model for confined concrete, J. Struct. Eng. 114 (8) (1988) 1804-1826.

[30] ACI-318-11, Building code requirements for reinforced concrete, ACI Committee 318, Detroit (MI), 2011.

[31] J. Tang, S. Hino, I. Kuroda, T. Ohta, Modeling of stress-strain relationships for steel and concrete in concrete filled circular steel tubular columns, Steel Constr. Eng. 3 (11) (1996) 35-46. 
Patel, V. I., Liang, Q. Q. and Hadi, M. N. S. (2020). Numerical simulations of circular high strength concrete-filled aluminum tubular short columns incorporating new concrete confinement model. Thin-Walled Structures, 147: 106492.

Figures and Tables

Table 1 Comparison of experimental and numerical ultimate axial loads.

\begin{tabular}{|c|c|c|c|c|c|c|c|c|c|c|c|}
\hline Specimen & $\begin{array}{c}D \\
(\mathrm{~mm})\end{array}$ & $\begin{array}{c}t \\
(\mathrm{~mm})\end{array}$ & $\frac{D}{t}$ & $\begin{array}{c}\sigma_{0.2} \\
(\mathrm{MPa})\end{array}$ & $\begin{array}{c}\sigma_{a u} \\
(\mathrm{MPa})\end{array}$ & $\begin{array}{c}E_{0} \\
(\mathrm{GPa}) \\
\end{array}$ & $\begin{array}{c}f_{c}^{\prime} \\
(\mathrm{MPa}) \\
\end{array}$ & $\begin{array}{l}P_{u \cdot \exp } \\
(\mathrm{kN})\end{array}$ & $\begin{array}{l}P_{u . m m} \\
(\mathrm{kN})\end{array}$ & $\frac{P_{u, \text { num }}}{P_{u . \text { exp }}}$ & Ref. \\
\hline CHS1C40 & 38 & 3.89 & 9.8 & 242.4 & 278.5 & 65 & 44.8 & 158.9 & 145.6 & 0.916 & \multirow{31}{*}{ [10] } \\
\hline CHS1C70 & 38 & 3.9 & 9.7 & 242.4 & 278.5 & 65 & 70.2 & 167.2 & 163.9 & 0.980 & \\
\hline CHS1C100 & 38 & 3.92 & 9.7 & 242.4 & 278.5 & 65 & 106 & 171.5 & 189.8 & 1.107 & \\
\hline CHS2C40 & 50 & 3.13 & 16 & 238.4 & 259.1 & 66.1 & 44.8 & 217 & 204.2 & 0.941 & \\
\hline CHS2C70 & 50 & 3.12 & 16 & 238.4 & 259.1 & 66.1 & 70.2 & 238.9 & 242.1 & 1.013 & \\
\hline CHS2C100 & 50 & 3.13 & 16 & 238.4 & 259.1 & 66.1 & 106 & 327.5 & 296.1 & 0.904 & \\
\hline CHS3C40 & 60 & 2.55 & 23.5 & 237.8 & 261.4 & 69.8 & 44.8 & 244.1 & 257.8 & 1.056 & \\
\hline CHS3C70 & 60 & 2.54 & 23.6 & 237.8 & 261.4 & 69.8 & 70.2 & 292.4 & 317.6 & 1.086 & \\
\hline CHS3C100 & 59.9 & 2.53 & 23.7 & 237.8 & 261.4 & 69.8 & 106 & 412.6 & 401.0 & 0.972 & \\
\hline CHS4C40 & 76.1 & 2.06 & 36.9 & 237 & 256 & 64.9 & 44.8 & 329.9 & 352.1 & 1.067 & \\
\hline CHS4C70 & 76 & 2.06 & 36.9 & 237 & 256 & 64.9 & 70.2 & 415.7 & 454.4 & 1.093 & \\
\hline CHS4C100 & 76 & 2.05 & 37.1 & 237 & 256 & 64.9 & 106 & 611.4 & 599.1 & 0.980 & \\
\hline CHS5C40 & 99.7 & 2.02 & 49.4 & 244.3 & 259.5 & 65.6 & 44.8 & 543.6 & 515.6 & 0.948 & \\
\hline CHS5C70 & 99.8 & 2.06 & 48.4 & 244.3 & 259.5 & 65.6 & 70.2 & 712 & 703.9 & 0.989 & \\
\hline CHS5C100 & 100 & 2.05 & 48.8 & 244.3 & 259.5 & 65.6 & 106 & 995.8 & 959.9 & 0.964 & \\
\hline CHS6C40 & 119.8 & 2.49 & 48.1 & 253.1 & 264.7 & 66.5 & 44.8 & 822.8 & 764.7 & 0.929 & \\
\hline CHS6C70 & 120 & 2.55 & 47.1 & 253.1 & 264.7 & 66.5 & 70.2 & 1010.3 & 1031.7 & 1.021 & \\
\hline CHS6C70-R & 119.6 & 2.48 & 48.2 & 253.1 & 264.7 & 66.5 & 70.2 & 1004 & 1014.4 & 1.010 & \\
\hline CHS6C100 & 119.9 & 2.48 & 48.3 & 253.1 & 264.7 & 66.5 & 106 & 1388.7 & 1376.7 & 0.991 & \\
\hline CHS7C40 & 150.1 & 2.53 & 59.3 & 267.9 & 282.9 & 64.9 & 44.8 & 1111.1 & 1107.9 & 0.997 & \\
\hline CHS7C70 & 150.1 & 2.54 & 59.1 & 267.9 & 282.9 & 64.9 & 70.2 & 1496.4 & 1500.9 & 1.003 & \\
\hline CHS7C100 & 149.9 & 2.53 & 59.2 & 267.9 & 282.9 & 64.9 & 106 & 2057.8 & 2042.5 & 0.993 & \\
\hline CHS8C40 & 150.2 & 5.03 & 29.9 & 216.9 & 251.9 & 65.8 & 44.8 & 1481.9 & 1507.8 & 1.017 & \\
\hline CHS8C70 & 150.2 & 5.04 & 29.8 & 216.9 & 251.9 & 65.8 & 70.2 & 1740.6 & 1880.7 & 1.081 & \\
\hline CHS8C100 & 150.2 & 5.03 & 29.9 & 216.9 & 251.9 & 65.8 & 106 & 2666.1 & 2403.9 & 0.902 & \\
\hline CHS9C40 & 160.1 & 4.03 & 39.7 & 254.2 & 272.9 & 66.6 & 44.8 & 1494.1 & 1492.5 & 0.999 & \\
\hline CHS9C70 & 160.5 & 4.07 & 39.4 & 254.2 & 272.9 & 66.6 & 70.2 & 1974.4 & 1939.0 & 0.982 & \\
\hline CHS9C100 & 160.5 & 4.06 & 39.5 & 254.2 & 272.9 & 66.6 & 106 & 2797.3 & 2550.3 & 0.912 & \\
\hline CHS10C40 & 180 & 3.71 & 48.5 & 264.9 & 287.1 & 68.7 & 44.8 & 1690.2 & 1755.6 & 1.039 & \\
\hline CHS10C70 & 180.4 & 3.69 & 48.9 & 264.9 & 287.1 & 68.7 & 70.2 & 2274.2 & 2300.7 & 1.012 & \\
\hline CHS10C100 & 180.5 & 3.75 & 48.1 & 264.9 & 287.1 & 68.7 & 106 & 3139.2 & 3085.9 & 0.983 & \\
\hline \multirow{2}{*}{\multicolumn{10}{|c|}{$\begin{array}{l}\text { Mean } \\
\text { Standard deviation (SD) }\end{array}$}} & 0.996 & \\
\hline & & & & & & & & & & 0.056 & \\
\hline \multicolumn{10}{|c|}{ Coefficient of variation (COV) } & 0.056 & \\
\hline
\end{tabular}


Patel, V. I., Liang, Q. Q. and Hadi, M. N. S. (2020). Numerical simulations of circular high strength concrete-filled aluminum tubular short columns incorporating new concrete confinement model. Thin-Walled Structures, 147: 106492.

Table 2 Comparison of lateral confining pressures provided by the carbon steel tube and aluminum tube.

\begin{tabular}{|c|c|c|c|c|c|c|c|c|c|c|}
\hline \multirow[b]{2}{*}{ Specimen } & \multirow[b]{2}{*}{$\begin{array}{l}P_{u . \exp } \\
(\mathrm{kN})\end{array}$} & \multicolumn{3}{|c|}{ Hu et al. model [12] } & \multicolumn{3}{|c|}{ Tang et al. model [31] } & \multicolumn{3}{|c|}{ Proposed Eq. (26) } \\
\hline & & $\begin{array}{c}f_{r p 1} \\
\text { (MPa) }\end{array}$ & $\begin{array}{l}P_{\text {u.num } 1} \\
(\mathrm{kN})\end{array}$ & $\frac{P_{u, \text { num } 1}}{P_{u, \text { exp }}}$ & $\begin{array}{c}f_{r p 2} \\
(\mathrm{MPa})\end{array}$ & $\begin{array}{c}P_{\text {u.mum } 2} \\
(\mathrm{kN})\end{array}$ & $\frac{P_{u, \text {.num } 2}}{P_{u, \text { exp }}}$ & $\begin{array}{c}f_{r p} \\
(\mathrm{MPa})\end{array}$ & $\begin{array}{l}P_{u . m u m} \\
(\mathrm{kN})\end{array}$ & $\frac{P_{u, \text { num }}}{P_{u \text {.exp }}}$ \\
\hline CHS1C40 & 158.9 & 6.20 & 150.8 & 0.949 & 6.35 & 151.3 & 0.952 & 4.41 & 145.6 & 0.916 \\
\hline CHS1C70 & 167.2 & 6.20 & 169.2 & 1.012 & -5.16 & 151.0 & 0.903 & 4.41 & 163.9 & 0.980 \\
\hline CHS1C100 & 171.5 & 6.20 & 195.1 & 1.137 & -43.16 & 176.9 & 1.031 & 4.41 & 189.8 & 1.107 \\
\hline CHS2C40 & 217 & 6.10 & 212.4 & 0.979 & 6.97 & 217.7 & 1.003 & 4.77 & 204.2 & 0.941 \\
\hline CHS2C70 & 238.9 & 6.10 & 250.3 & 1.048 & 1.82 & 224.0 & 0.938 & 4.77 & 242.1 & 1.013 \\
\hline CHS2C100 & 327.5 & 6.10 & 304.3 & 0.929 & -17.56 & 266.7 & 0.814 & 4.77 & 296.1 & 0.904 \\
\hline CHS3C40 & 244.1 & 5.72 & 268.9 & 1.102 & 6.71 & 278.5 & 1.141 & 4.58 & 257.8 & 1.056 \\
\hline CHS3C70 & 292.4 & 5.71 & 328.6 & 1.124 & 4.23 & 314.4 & 1.075 & 4.57 & 317.6 & 1.086 \\
\hline CHS3C100 & 412.6 & 5.69 & 411.9 & 0.998 & -7.02 & 356.7 & 0.865 & 4.57 & 401.0 & 0.972 \\
\hline CHS4C40 & 329.9 & 3.06 & 344.2 & 1.043 & 5.60 & 386.6 & 1.172 & 3.53 & 352.1 & 1.067 \\
\hline CHS4C70 & 415.7 & 3.07 & 446.7 & 1.074 & 4.65 & 472.9 & 1.138 & 3.53 & 454.4 & 1.093 \\
\hline CHS4C100 & 611.4 & 3.03 & 591.1 & 0.967 & -1.52 & 540.6 & 0.884 & 3.51 & 599.1 & 0.980 \\
\hline CHS5C40 & 543.6 & 1.09 & 492.1 & 0.905 & 4.59 & 600.3 & 1.104 & 1.87 & 515.6 & 0.948 \\
\hline CHS5C70 & 712 & 1.10 & 676.4 & 0.950 & 4.25 & 773.8 & 1.087 & 2.00 & 703.9 & 0.989 \\
\hline CHS5C100 & 995.8 & 1.10 & 933.5 & 0.937 & 0.12 & 903.5 & 0.907 & 1.95 & 959.9 & 0.964 \\
\hline CHS6C40 & 822.8 & 1.14 & 713.7 & 0.867 & 4.79 & 875.4 & 1.064 & 2.31 & 764.7 & 0.929 \\
\hline CHS6C70 & 1010.3 & 1.15 & 975.3 & 0.965 & 4.74 & 1134.2 & 1.123 & 2.44 & 1031.7 & 1.021 \\
\hline CHS6C70-R & 1004 & 1.14 & 963.7 & 0.960 & 4.63 & 1119.1 & 1.115 & 2.30 & 1014.4 & 1.010 \\
\hline CHS6C100 & 1388.7 & 1.14 & 1326.1 & 0.955 & 1.16 & 1326.9 & 0.956 & 2.28 & 1376.7 & 0.991 \\
\hline CHS7C40 & 1111.1 & 1.10 & 1048.2 & 0.943 & 3.90 & 1255.8 & 1.130 & 1.93 & 1107.9 & 0.997 \\
\hline CHS7C70 & 1496.4 & 1.11 & 1437.9 & 0.961 & 4.07 & 1660.9 & 1.110 & 1.96 & 1500.9 & 1.003 \\
\hline CHS7C100 & 2057.8 & 1.11 & 1980.5 & 0.962 & 1.92 & 2040.8 & 0.992 & 1.94 & 2042.5 & 0.993 \\
\hline CHS8C40 & 1481.9 & 4.08 & 1409.1 & 0.951 & 5.70 & 1511.4 & 1.020 & 5.64 & 1507.8 & 1.017 \\
\hline CHS8C70 & 1740.6 & 4.09 & 1782.3 & 1.024 & 3.96 & 1774.2 & 1.019 & 5.65 & 1880.7 & 1.081 \\
\hline CHS8C100 & 2666.1 & 4.08 & 2305.2 & 0.865 & -4.47 & 2047.3 & 0.768 & 5.64 & 2403.9 & 0.902 \\
\hline CHS9C40 & 1494.1 & 2.69 & 1453.8 & 0.973 & 5.55 & 1666.3 & 1.115 & 3.21 & 1492.5 & 0.999 \\
\hline CHS9C70 & 1974.4 & 2.75 & 1903.0 & 0.964 & 5.50 & 2108.5 & 1.068 & 3.24 & 1939.0 & 0.982 \\
\hline CHS9C100 & 2797.3 & 2.73 & 2513.4 & 0.898 & 1.69 & 2435.5 & 0.871 & 3.23 & 2550.3 & 0.912 \\
\hline CHS10C40 & 1690.2 & 1.19 & 1583.8 & 0.937 & 4.81 & 1946.2 & 1.151 & 2.93 & 1755.6 & 1.039 \\
\hline CHS10C70 & 2274.2 & 1.19 & 2129.6 & 0.936 & 5.03 & 2519.6 & 1.108 & 2.90 & 2300.7 & 1.012 \\
\hline CHS10C100 & 3139.2 & 1.20 & 2908.0 & 0.926 & 2.66 & 3054.5 & 0.973 & 2.97 & 3085.9 & 0.983 \\
\hline \multicolumn{4}{|l|}{ Mean } & 0.976 & & & 1.019 & & & 0.996 \\
\hline \multicolumn{4}{|c|}{ Standard deviation (SD) } & 0.067 & & & 0.110 & & & 0.056 \\
\hline \multicolumn{4}{|c|}{ Coefficient of variation (COV) } & 0.069 & & & 0.108 & & & 0.056 \\
\hline
\end{tabular}


Patel, V. I., Liang, Q. Q. and Hadi, M. N. S. (2020). Numerical simulations of circular high strength concrete-filled aluminum tubular short columns incorporating new concrete confinement model. Thin-Walled Structures, 147: 106492.

Table 3 Geometric and material properties of CFAT columns employed in the parametric study.

\begin{tabular}{|c|c|c|c|c|c|c|c|}
\hline \multirow{3}{*}{ Parameter } & Specimen & $D(\mathrm{~mm})$ & $t(\mathrm{~mm})$ & $\frac{D}{t}$ & $\sigma_{0.2}(\mathrm{MPa})$ & $\sigma_{a u}(\mathrm{MPa})$ & $f_{c}^{\prime}(\mathrm{MPa})$ \\
\hline \multirow{3}{*}{$D / t$ ratio } & $\mathrm{C} 1$ & 400 & 6.7 & 40 & 260 & 290 & 65 \\
\cline { 2 - 8 } & $\mathrm{C} 2$ & 400 & 5.7 & 60 & 260 & 290 & 65 \\
\cline { 2 - 8 } & $\mathrm{C} 3$ & 400 & 5 & 80 & 260 & 290 & 65 \\
\cline { 2 - 8 } & $\mathrm{C} 4$ & 400 & 4 & 100 & 260 & 290 & 65 \\
\hline \multirow{3}{*}{ Aluminum proof stress } & $\mathrm{C} 5$ & 500 & 10 & 50 & 220 & 250 & 50 \\
\cline { 2 - 8 } & $\mathrm{C} 6$ & 500 & 10 & 50 & 240 & 260 & 50 \\
\cline { 2 - 8 } & $\mathrm{C} 7$ & 500 & 10 & 50 & 250 & 260 & 50 \\
\cline { 2 - 8 } & $\mathrm{C} 8$ & 500 & 10 & 50 & 270 & 280 & 50 \\
\hline \multirow{3}{*}{ Concrete strength } & $\mathrm{C} 9$ & 600 & 10 & 60 & 250 & 260 & 40 \\
\cline { 2 - 8 } & $\mathrm{C} 10$ & 600 & 10 & 60 & 250 & 260 & 65 \\
\cline { 2 - 8 } & $\mathrm{C} 11$ & 600 & 10 & 60 & 250 & 260 & 80 \\
\cline { 2 - 8 } & $\mathrm{C} 12$ & 600 & 10 & 60 & 250 & 260 & 100 \\
\hline CFST and CFAT columns & $\mathrm{C} 13$ & 700 & 10 & 70 & 270 & 280 & 80 \\
\hline
\end{tabular}


Patel, V. I., Liang, Q. Q. and Hadi, M. N. S. (2020). Numerical simulations of circular high strength concrete-filled aluminum tubular short columns incorporating new concrete confinement model. Thin-Walled Structures, 147: 106492.

Table 4 Verification of the design model.

\begin{tabular}{|c|c|c|c|c|c|c|c|c|c|}
\hline Specimen & $\frac{D}{t}$ & $\gamma_{c}$ & $f_{c}(\mathrm{MPa})$ & $\begin{array}{c}f_{r p} \\
(\mathrm{MPa})\end{array}$ & $\gamma_{a}$ & $\sigma_{0.2}(\mathrm{MPa})$ & $\begin{array}{c}P_{u} \\
(\mathrm{kN})\end{array}$ & $\begin{array}{c}P_{\text {u.cd }} \\
(\mathrm{kN})\end{array}$ & $\frac{P_{\text {ucal }}}{P_{u}}$ \\
\hline CHS1C40 & 9.8 & 1.000 & 44.8 & 4.410 & 1.114 & 242.4 & 158.9 & 157.6 & 0.992 \\
\hline CHS1C70 & 9.7 & 1.000 & 70.2 & 4.410 & 1.114 & 242.4 & 167.2 & 176.1 & 1.053 \\
\hline CHS1C100 & 9.7 & 1.000 & 106 & 4.408 & 1.115 & 242.4 & 171.5 & 202.1 & 1.178 \\
\hline CHS2C40 & 16.0 & 1.000 & 44.8 & 4.768 & 1.013 & 238.4 & 217 & 208.0 & 0.959 \\
\hline CHS2C70 & 16.0 & 1.000 & 70.2 & 4.767 & 1.013 & 238.4 & 238.9 & 245.9 & 1.029 \\
\hline CHS2C100 & 16.0 & 1.000 & 106 & 4.768 & 1.013 & 238.4 & 327.5 & 300.0 & 0.916 \\
\hline CHS3C40 & 23.5 & 1.000 & 44.8 & 4.576 & 0.941 & 237.8 & 244.1 & 253.4 & 1.038 \\
\hline CHS3C70 & 23.6 & 1.000 & 70.2 & 4.572 & 0.940 & 237.8 & 292.4 & 313.2 & 1.071 \\
\hline CHS3C100 & 23.7 & 1.000 & 106 & 4.569 & 0.940 & 237.8 & 412.6 & 396.5 & 0.961 \\
\hline CHS4C40 & 36.9 & 1.000 & 44.8 & 3.529 & 0.863 & 237 & 329.9 & 339.1 & 1.028 \\
\hline CHS4C70 & 36.9 & 1.000 & 70.2 & 3.534 & 0.863 & 237 & 415.7 & 441.5 & 1.062 \\
\hline CHS4C100 & 37.1 & 1.000 & 106 & 3.514 & 0.862 & 237 & 611.4 & 586.2 & 0.959 \\
\hline CHS5C40 & 49.4 & 0.999 & 44.8 & 1.868 & 0.816 & 244.3 & 543.6 & 500.4 & 0.921 \\
\hline CHS5C70 & 48.4 & 0.999 & 70.2 & 2.004 & 0.819 & 244.3 & 712 & 690.1 & 0.969 \\
\hline CHS5C100 & 48.8 & 0.999 & 106 & 1.955 & 0.818 & 244.3 & 995.8 & 948.9 & 0.953 \\
\hline CHS6C40 & 48.1 & 0.975 & 44.8 & 2.313 & 0.820 & 253.1 & 822.8 & 741.0 & 0.901 \\
\hline CHS6C70 & 47.1 & 0.975 & 70.2 & 2.441 & 0.823 & 253.1 & 1010.3 & 1009.6 & 0.999 \\
\hline CHS6C70-R & 48.2 & 0.975 & 70.2 & 2.299 & 0.820 & 253.1 & 1004 & 993.3 & 0.989 \\
\hline CHS6C100 & 48.3 & 0.975 & 106 & 2.284 & 0.819 & 253.1 & 1388.7 & 1359.2 & 0.979 \\
\hline CHS7C40 & 59.3 & 0.945 & 44.8 & 1.932 & 0.788 & 267.9 & 1111.1 & 1077.7 & 0.970 \\
\hline CHS7C70 & 59.1 & 0.945 & 70.2 & 1.964 & 0.788 & 267.9 & 1496.4 & 1477.3 & 0.987 \\
\hline CHS7C100 & 59.2 & 0.945 & 106 & 1.942 & 0.788 & 267.9 & 2057.8 & 2029.0 & 0.986 \\
\hline CHS8C40 & 29.9 & 0.949 & 44.8 & 5.638 & 0.899 & 216.9 & 1481.9 & 1459.7 & 0.985 \\
\hline CHS8C70 & 29.8 & 0.949 & 70.2 & 5.646 & 0.899 & 216.9 & 1740.6 & 1832.7 & 1.053 \\
\hline CHS8C100 & 29.9 & 0.949 & 106 & 5.638 & 0.899 & 216.9 & 2666.1 & 2355.7 & 0.884 \\
\hline CHS9C40 & 39.7 & 0.939 & 44.8 & 3.213 & 0.851 & 254.2 & 1494.1 & 1430.1 & 0.957 \\
\hline CHS9C70 & 39.4 & 0.939 & 70.2 & 3.236 & 0.852 & 254.2 & 1974.4 & 1876.4 & 0.950 \\
\hline CHS9C100 & 39.5 & 0.939 & 106 & 3.229 & 0.851 & 254.2 & 2797.3 & 2487.7 & 0.889 \\
\hline CHS10C40 & 48.5 & 0.923 & 44.8 & 2.933 & 0.819 & 264.9 & 1690.2 & 1694.1 & 1.002 \\
\hline CHS10C70 & 48.9 & 0.923 & 70.2 & 2.896 & 0.817 & 264.9 & 2274.2 & 2245.6 & 0.987 \\
\hline CHS10C100 & 48.1 & 0.923 & 106 & 2.969 & 0.820 & 264.9 & 3139.2 & 3037.3 & 0.968 \\
\hline $\mathrm{C} 1$ & 40.0 & 0.850 & 65 & 3.368 & 0.850 & 260 & 8880.6 & 10538.4 & 1.187 \\
\hline $\mathrm{C} 2$ & 59.7 & 0.850 & 65 & 1.112 & 0.787 & 260 & 8007 & 8714.0 & 1.088 \\
\hline $\mathrm{C} 3$ & 80.0 & 0.850 & 65 & 0.000 & 0.744 & 260 & 7790.9 & 7799.9 & 1.001 \\
\hline $\mathrm{C} 4$ & 100.0 & 0.850 & 65 & 0.000 & 0.713 & 260 & 7496.7 & 7589.8 & 1.012 \\
\hline $\mathrm{C} 5$ & 50.0 & 0.850 & 50 & 1.957 & 0.814 & 220 & 12277.8 & 11899.0 & 0.969 \\
\hline C6 & 50.0 & 0.850 & 50 & 1.694 & 0.814 & 240 & 12339.2 & 11954.4 & 0.969 \\
\hline C7 & 50.0 & 0.850 & 50 & 1.943 & 0.814 & 250 & 12652.5 & 12264.5 & 0.969 \\
\hline $\mathrm{C} 8$ & 50.0 & 0.850 & 50 & 3.202 & 0.814 & 270 & 13910.7 & 13449.6 & 0.967 \\
\hline C9 & 60.0 & 0.850 & 40 & 0.312 & 0.786 & 250 & 13379.2 & 12963.1 & 0.969 \\
\hline $\mathrm{C} 10$ & 60.0 & 0.850 & 65 & 0.312 & 0.786 & 250 & 18866.4 & 18577.6 & 0.985 \\
\hline $\mathrm{C} 11$ & 60.0 & 0.850 & 80 & 0.312 & 0.786 & 250 & 22180.4 & 21946.2 & 0.989 \\
\hline $\mathrm{C} 12$ & 60.0 & 0.850 & 100 & 0.312 & 0.786 & 250 & 26613.2 & 26437.7 & 0.993 \\
\hline $\mathrm{C} 13$ & 70.0 & 0.850 & 80 & 0.478 & 0.763 & 270 & 29996.2 & 29872.5 & 0.996 \\
\hline \multirow{2}{*}{\multicolumn{9}{|c|}{$\begin{array}{l}\text { Mean } \\
\text { Standard deviation (SD) }\end{array}$}} & 0.993 \\
\hline & & & & & & & & & 0.061 \\
\hline \multicolumn{9}{|c|}{ Coefficient of variation (COV) } & 0.061 \\
\hline
\end{tabular}


Patel, V. I., Liang, Q. Q. and Hadi, M. N. S. (2020). Numerical simulations of circular high strength concrete-filled aluminum tubular short columns incorporating new concrete confinement model. Thin-Walled Structures, 147: 106492.

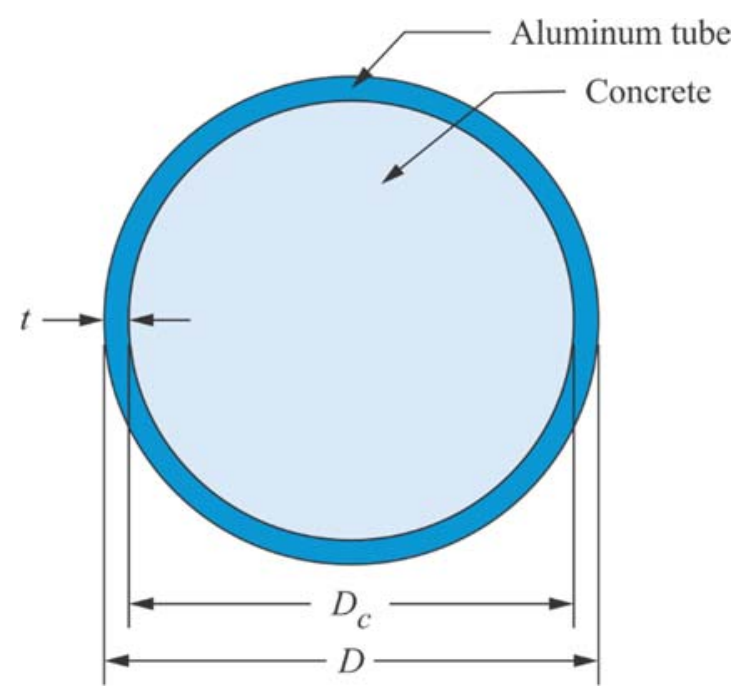

Fig. 1. Cross-section of circular CFAT column.

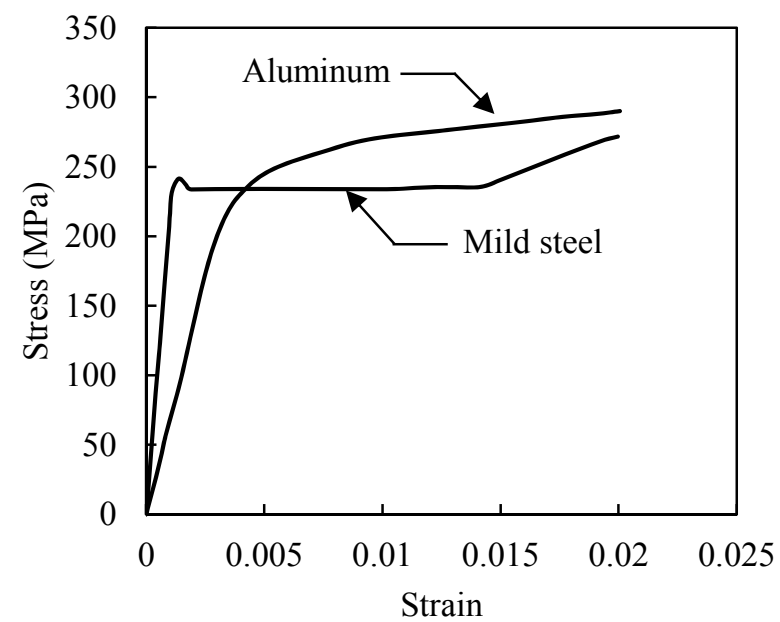

Fig. 2. Comparison of stress-strain curves for aluminum and steel materials. 
Patel, V. I., Liang, Q. Q. and Hadi, M. N. S. (2020). Numerical simulations of circular high strength concrete-filled aluminum tubular short columns incorporating new concrete confinement model. Thin-Walled Structures, 147: 106492.

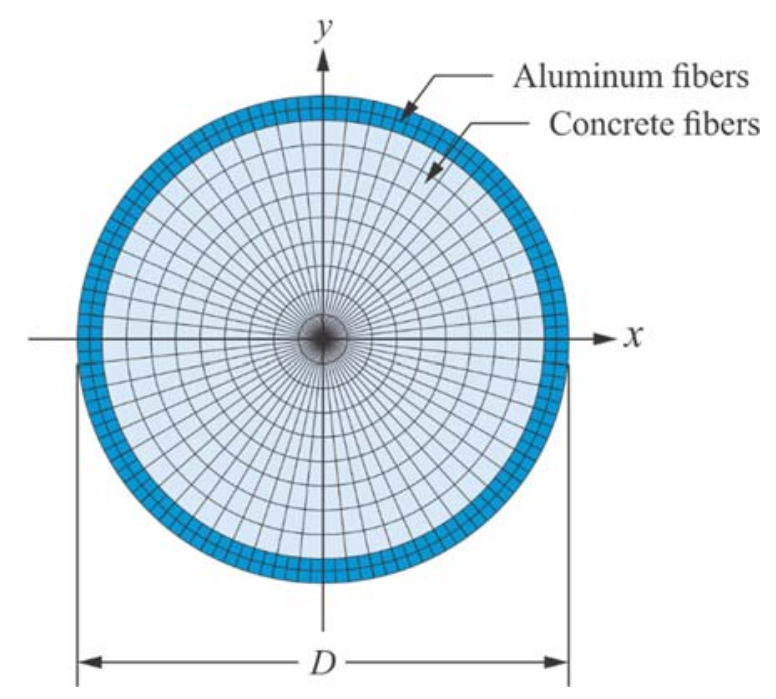

Fig. 3. Typical discretization of circular CFAT column section.

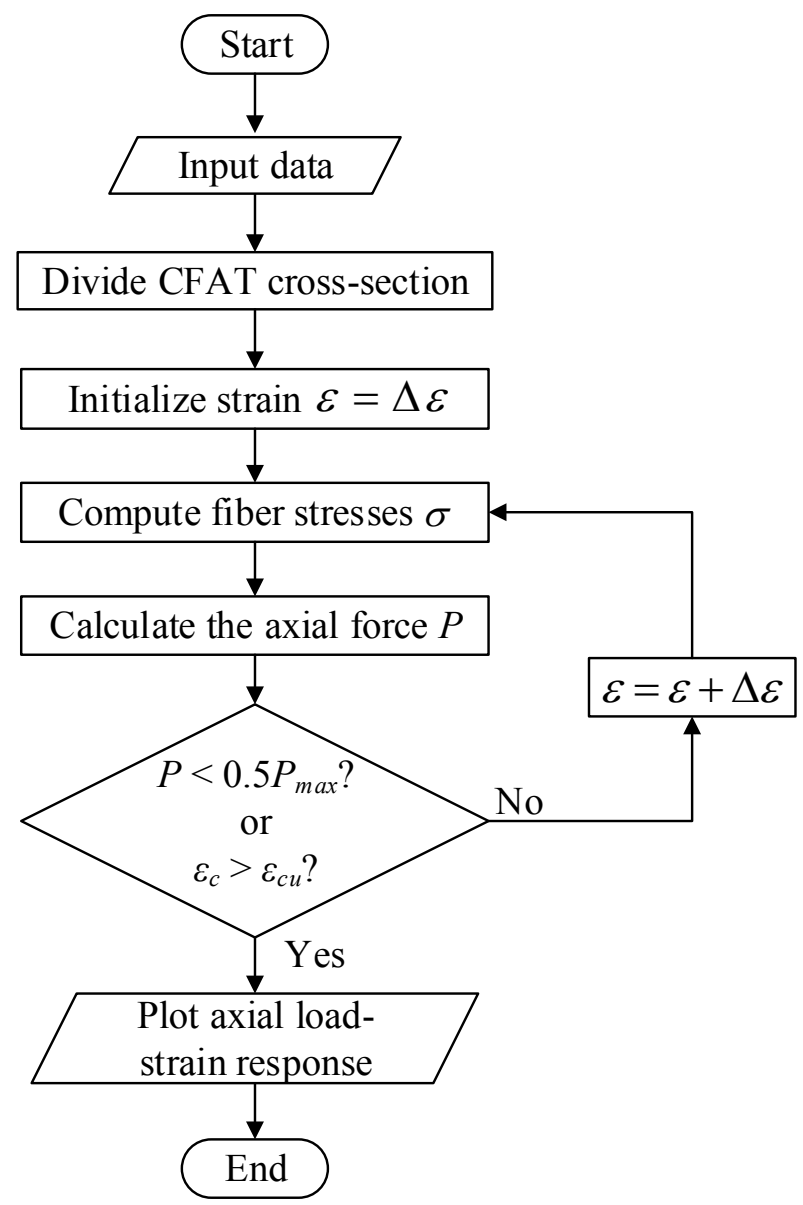

Fig. 4. Computer flowchart for computing the load-strain curve of circular CFAT short columns. 
Patel, V. I., Liang, Q. Q. and Hadi, M. N. S. (2020). Numerical simulations of circular high strength concrete-filled aluminum tubular short columns incorporating new concrete confinement model. Thin-Walled Structures, 147: 106492.

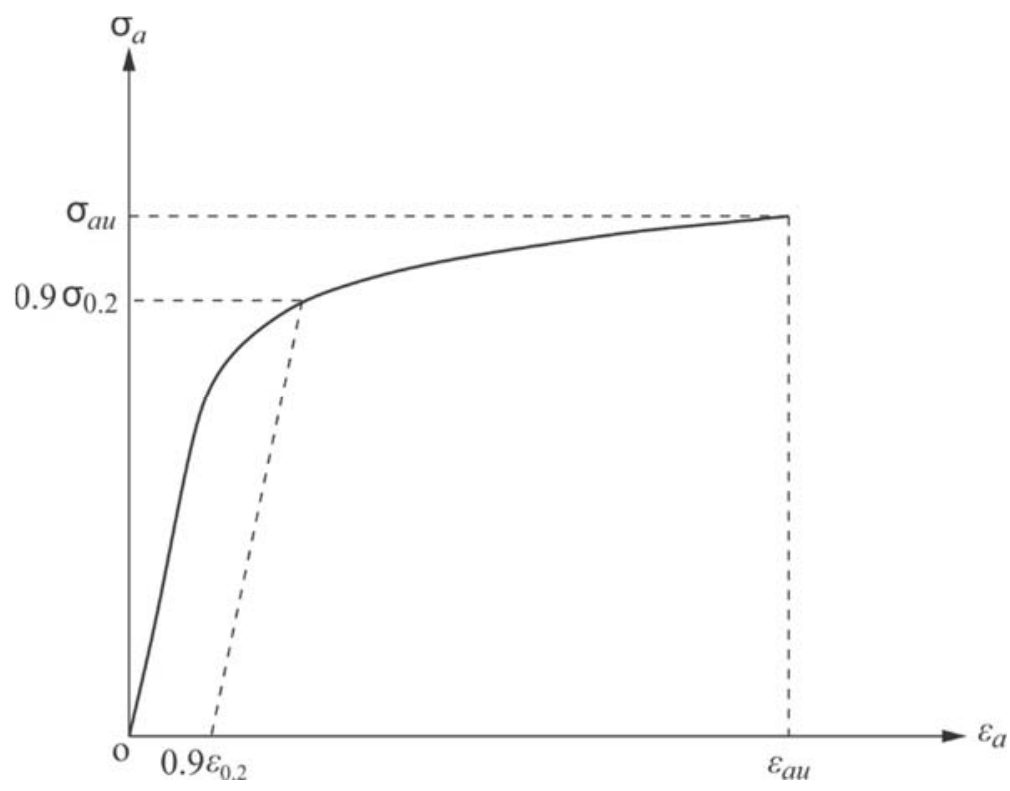

Fig. 5. Stress-strain curve for aluminum.

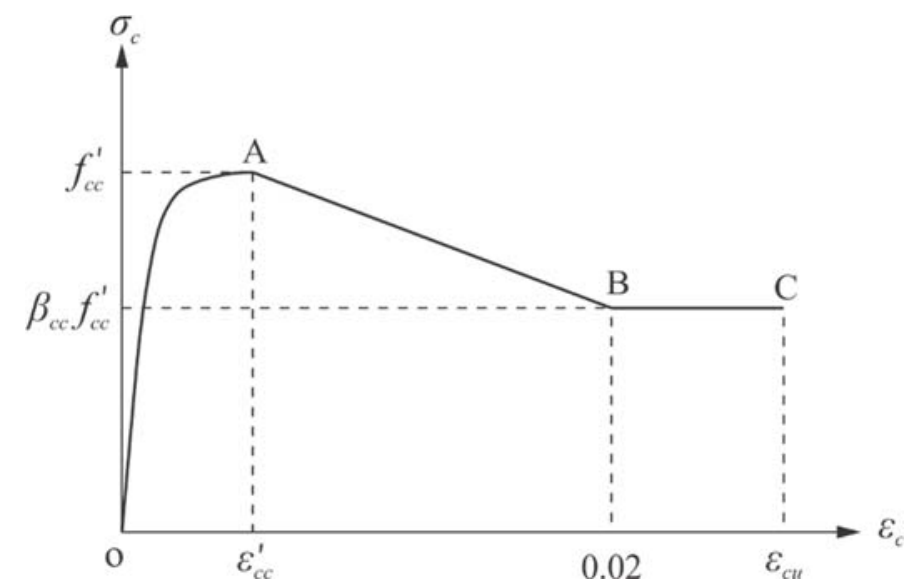

Fig. 6. Stress-strain curve for confined concrete. 
Patel, V. I., Liang, Q. Q. and Hadi, M. N. S. (2020). Numerical simulations of circular high strength concrete-filled aluminum tubular short columns incorporating new concrete confinement model. Thin-Walled Structures, 147: 106492.

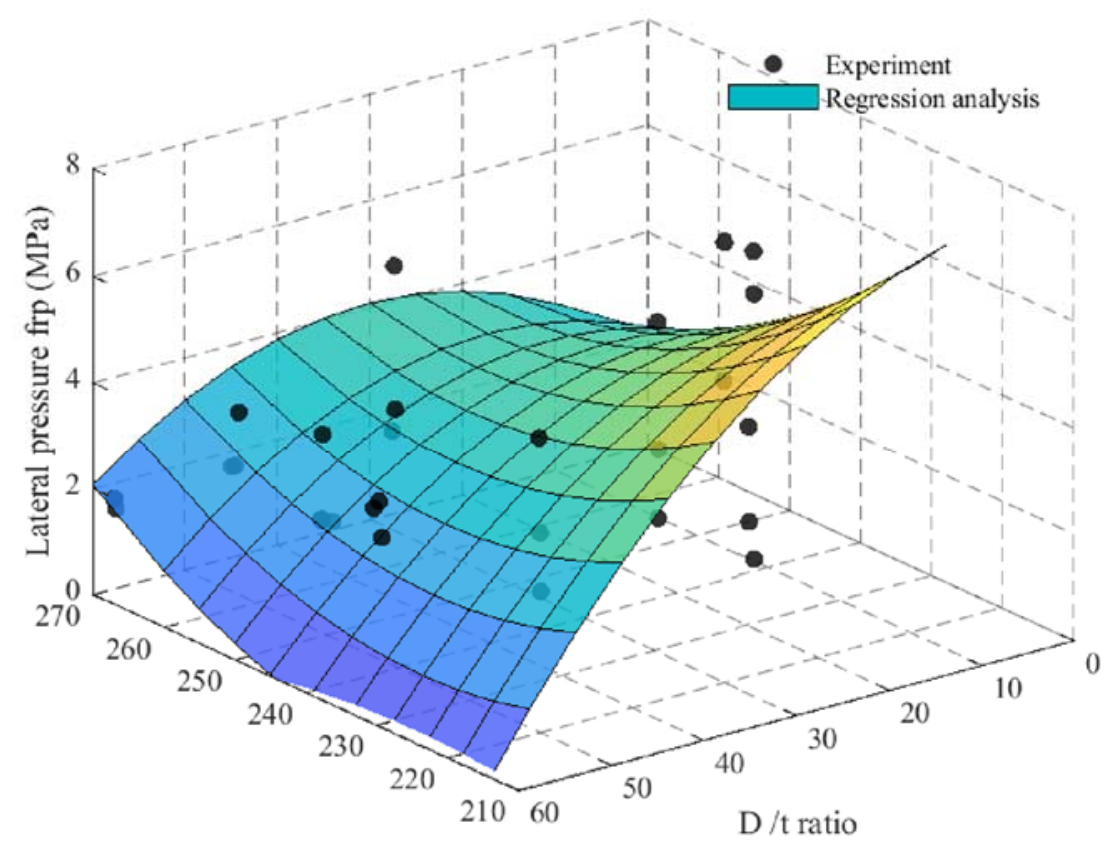

Aluminum $0.2 \%$ proof stress

Fig. 7. Comparison of lateral confining pressures predicted by the proposed concrete confinement model and obtained from experiments [10]. 
Patel, V. I., Liang, Q. Q. and Hadi, M. N. S. (2020). Numerical simulations of circular high strength concrete-filled aluminum tubular short columns incorporating new concrete confinement model. Thin-Walled Structures, 147: 106492.

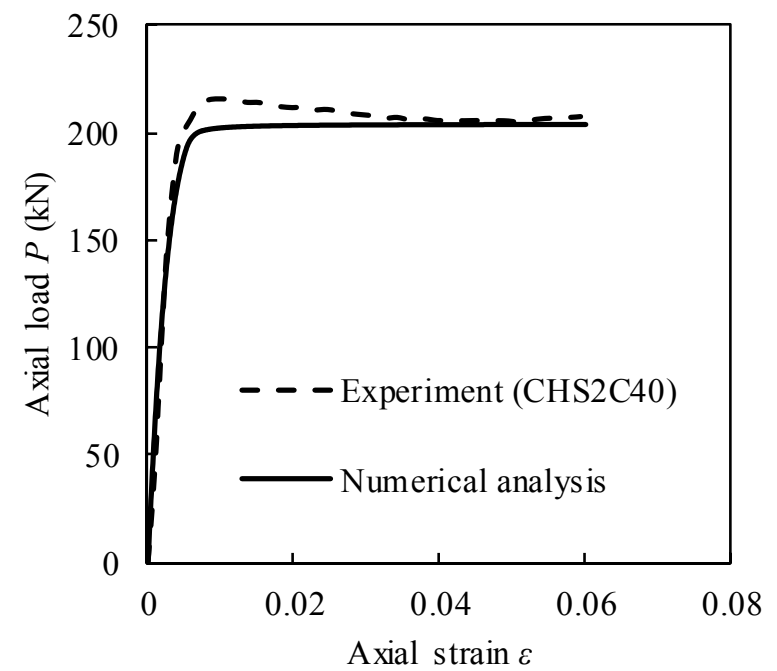

(a)

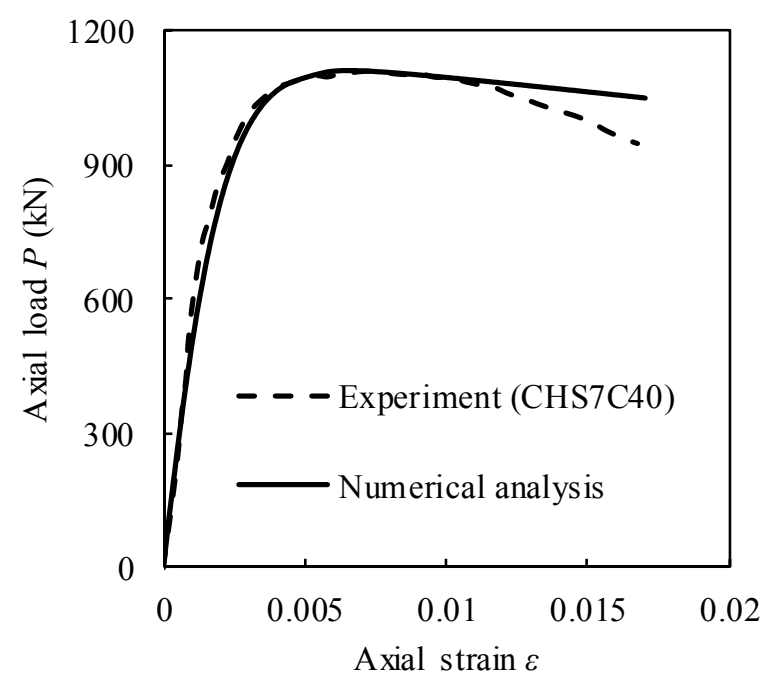

(c)

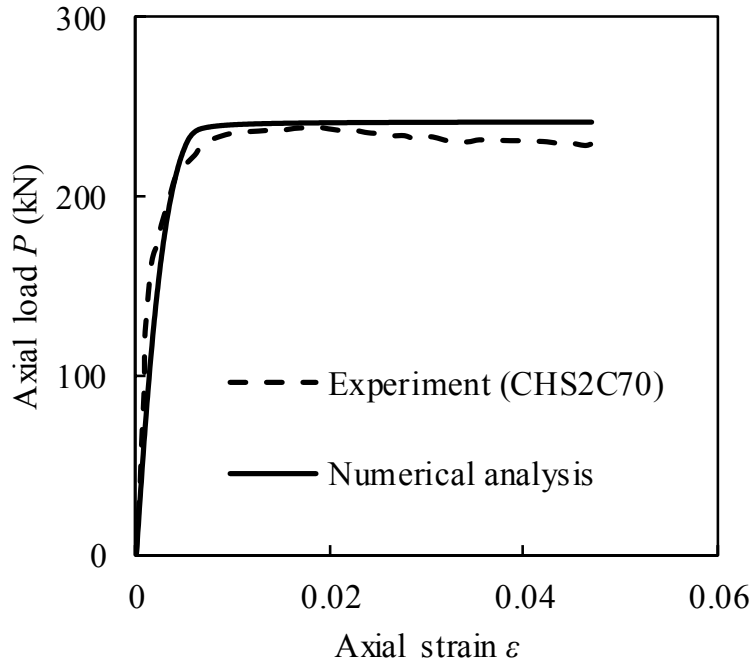

(b)

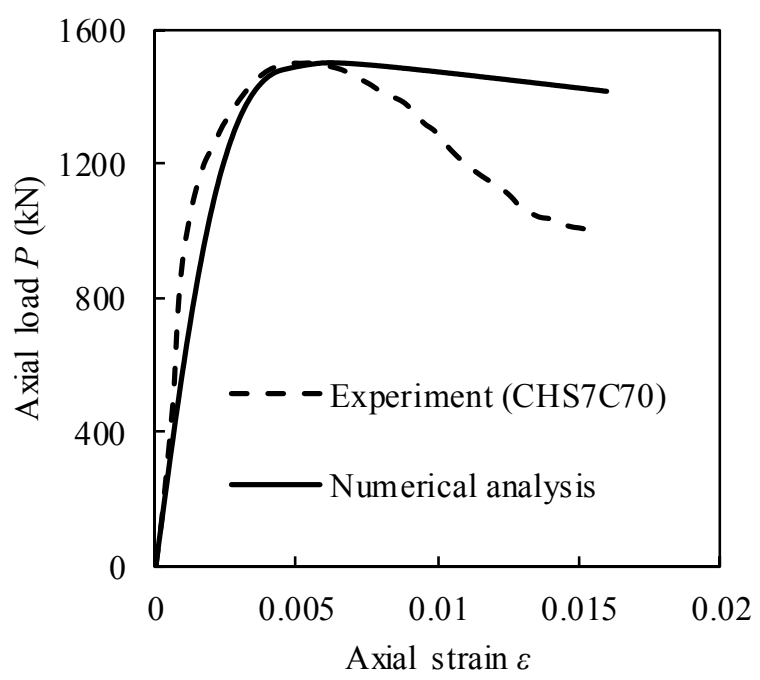

(d)

Fig. 8. Comparison of axial load-strain responses predicted by the developed computational model and obtained from experimental results [10]. 
Patel, V. I., Liang, Q. Q. and Hadi, M. N. S. (2020). Numerical simulations of circular high strength concrete-filled aluminum tubular short columns incorporating new concrete confinement model. Thin-Walled Structures, 147: 106492.

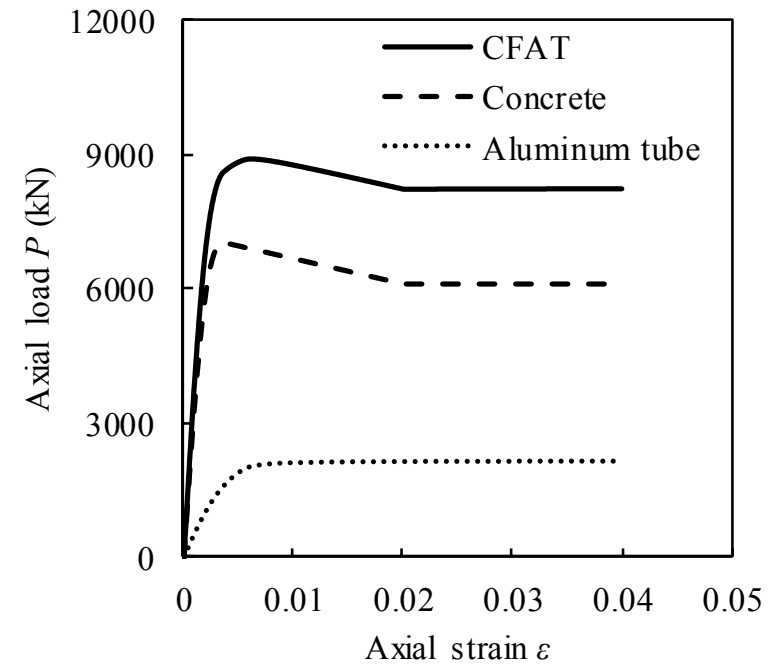

(a) $D / t=60$

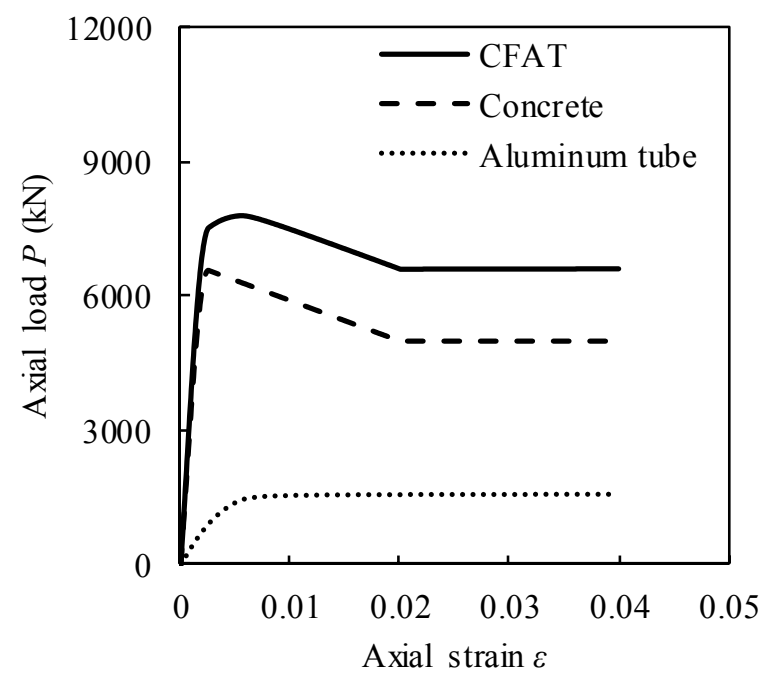

(c) $D / t=80$

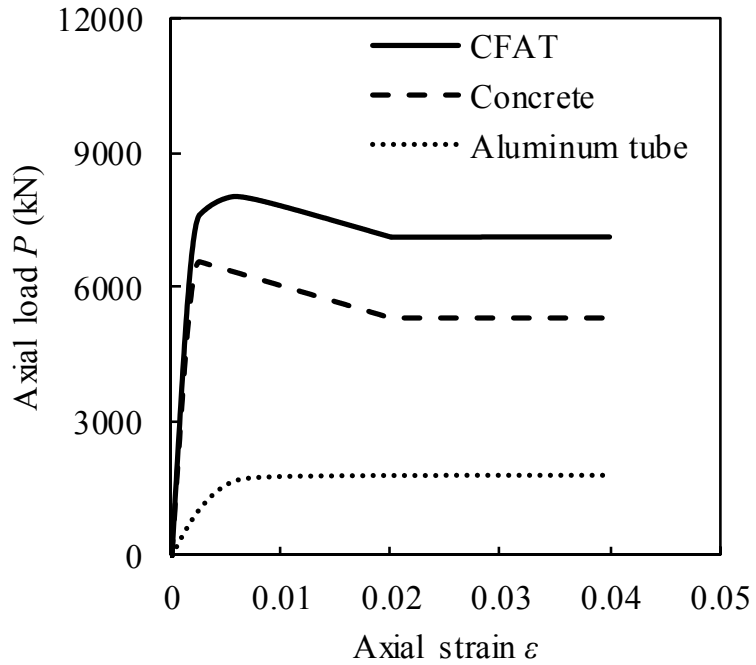

(b) $D / t=70$

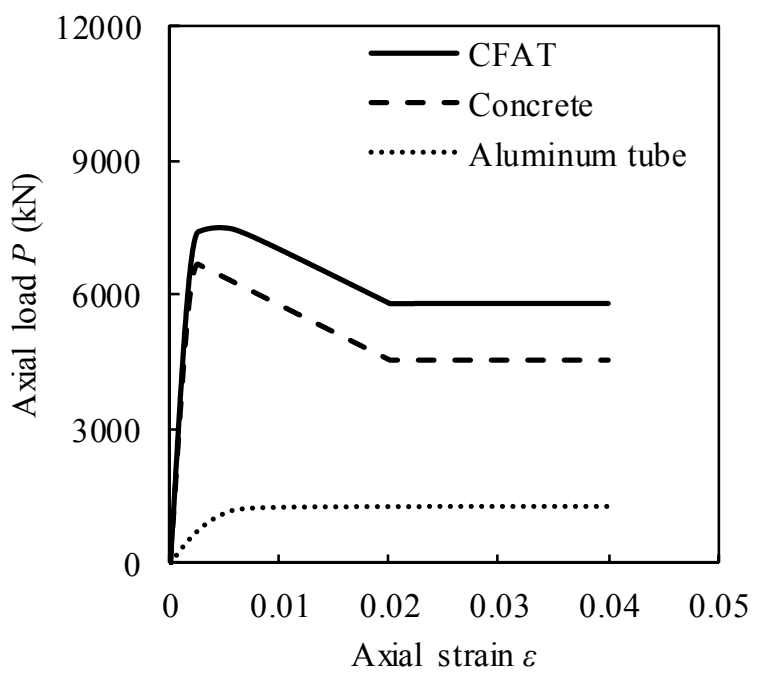

(d) $D / t=100$

Fig. 9. Axial load distributions in circular CFAT short columns with various $D / t$ ratios.

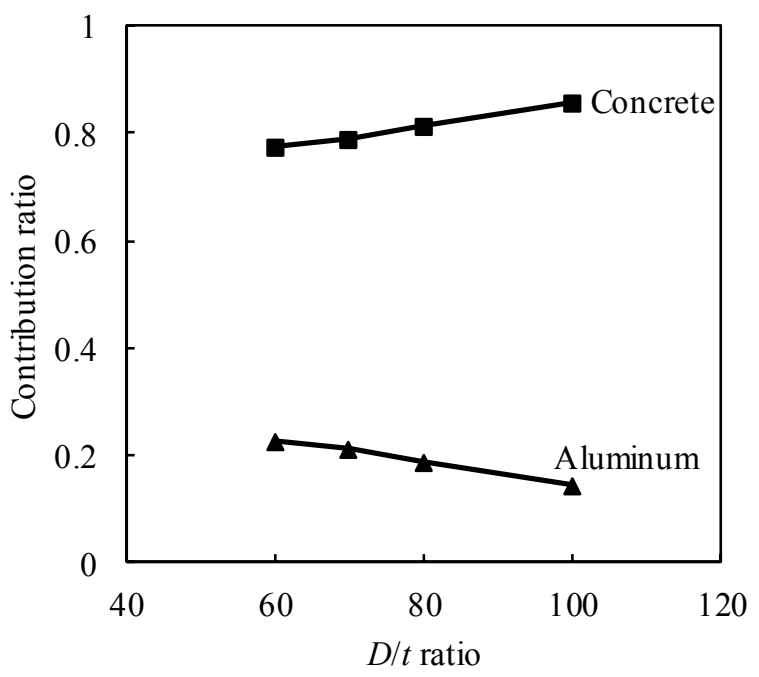

Fig. 10. Effect of $D / t$ ratio on contribution ratios. 
Patel, V. I., Liang, Q. Q. and Hadi, M. N. S. (2020). Numerical simulations of circular high strength concrete-filled aluminum tubular short columns incorporating new concrete confinement model. Thin-Walled Structures, 147: 106492.
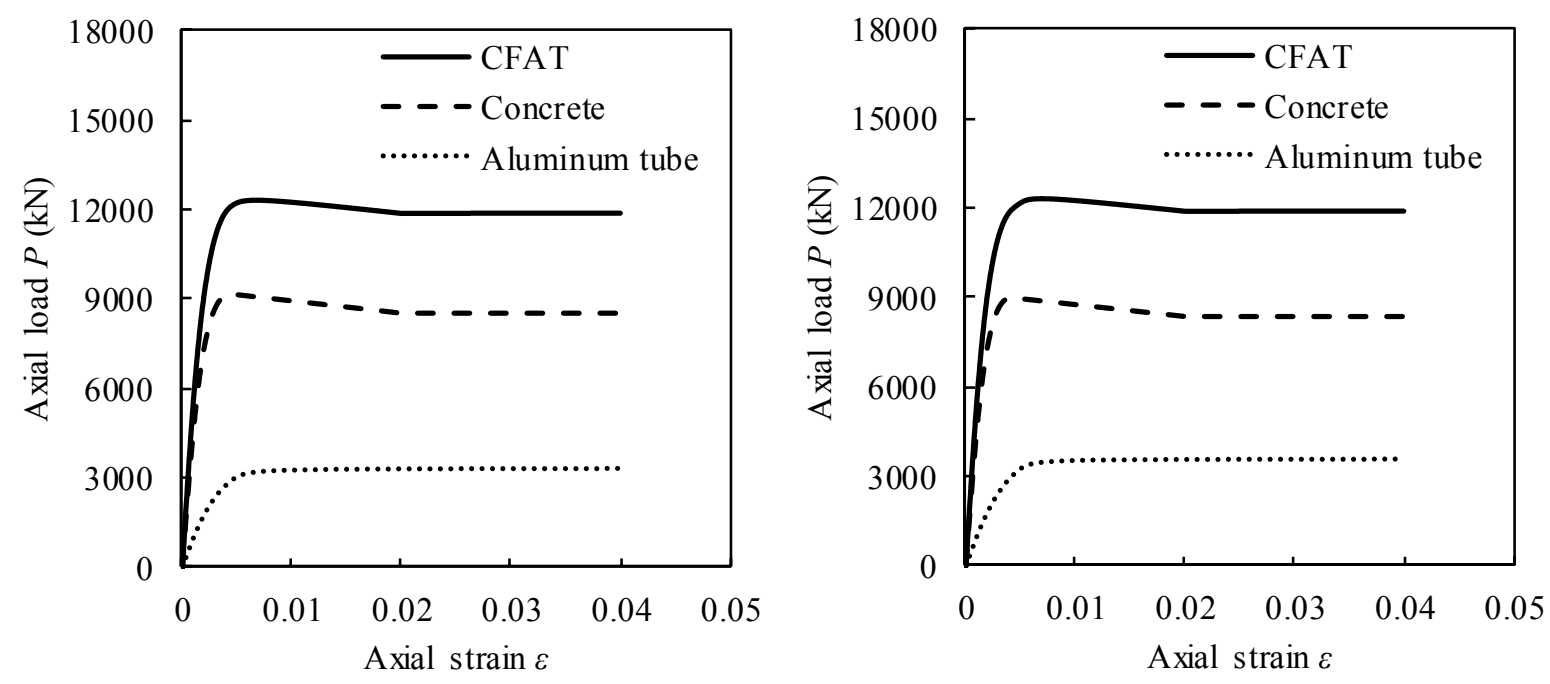

(a) $\sigma_{0.2}=220 \mathrm{MPa}$

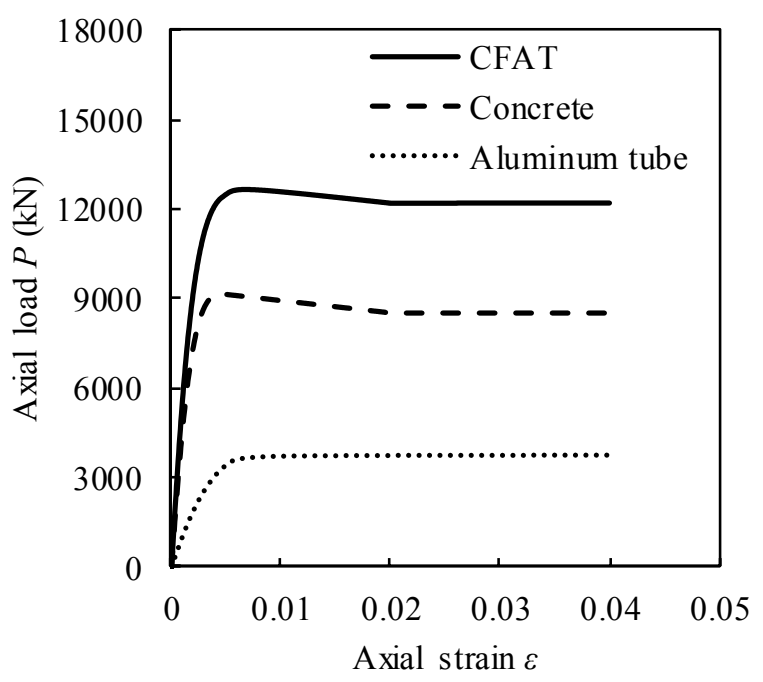

(b) $\sigma_{0.2}=240 \mathrm{MPa}$

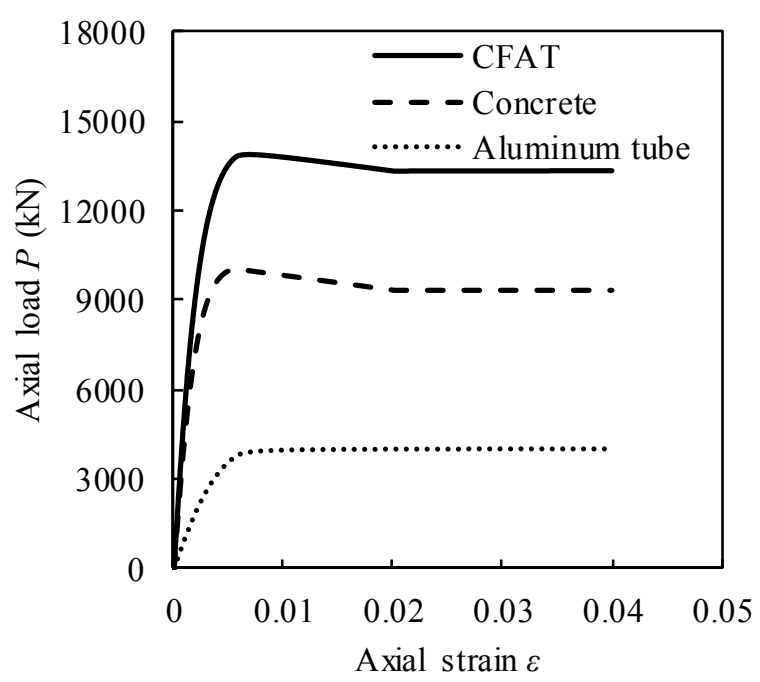

(c) $\sigma_{0.2}=250 \mathrm{MPa}$

(d) $\sigma_{0.2}=270 \mathrm{MPa}$

Fig. 11. Axial load distributions in circular CFAT short columns with various aluminum proof strengths.

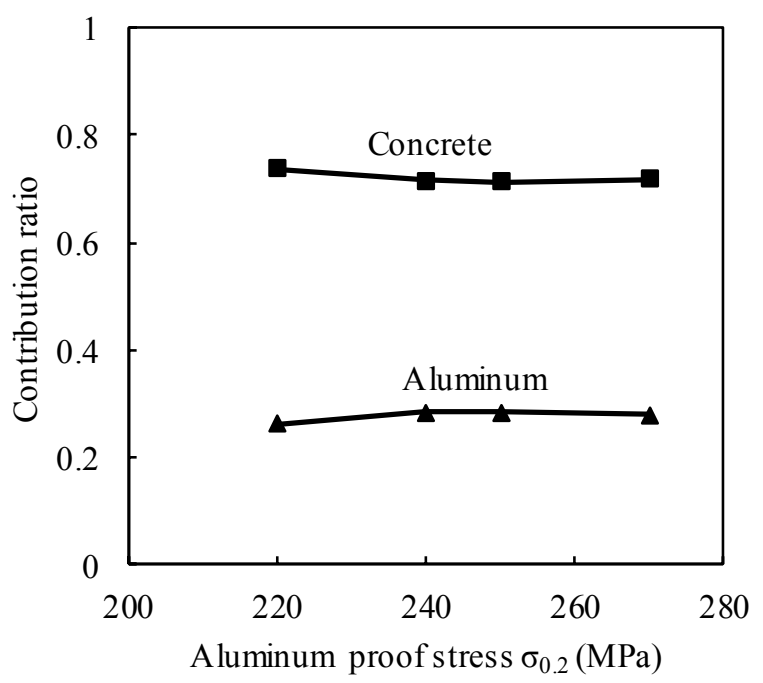

Fig. 12. Effect of aluminum proof stress on contribution ratios. 
Patel, V. I., Liang, Q. Q. and Hadi, M. N. S. (2020). Numerical simulations of circular high strength concrete-filled aluminum tubular short columns incorporating new concrete confinement model. Thin-Walled Structures, 147: 106492.
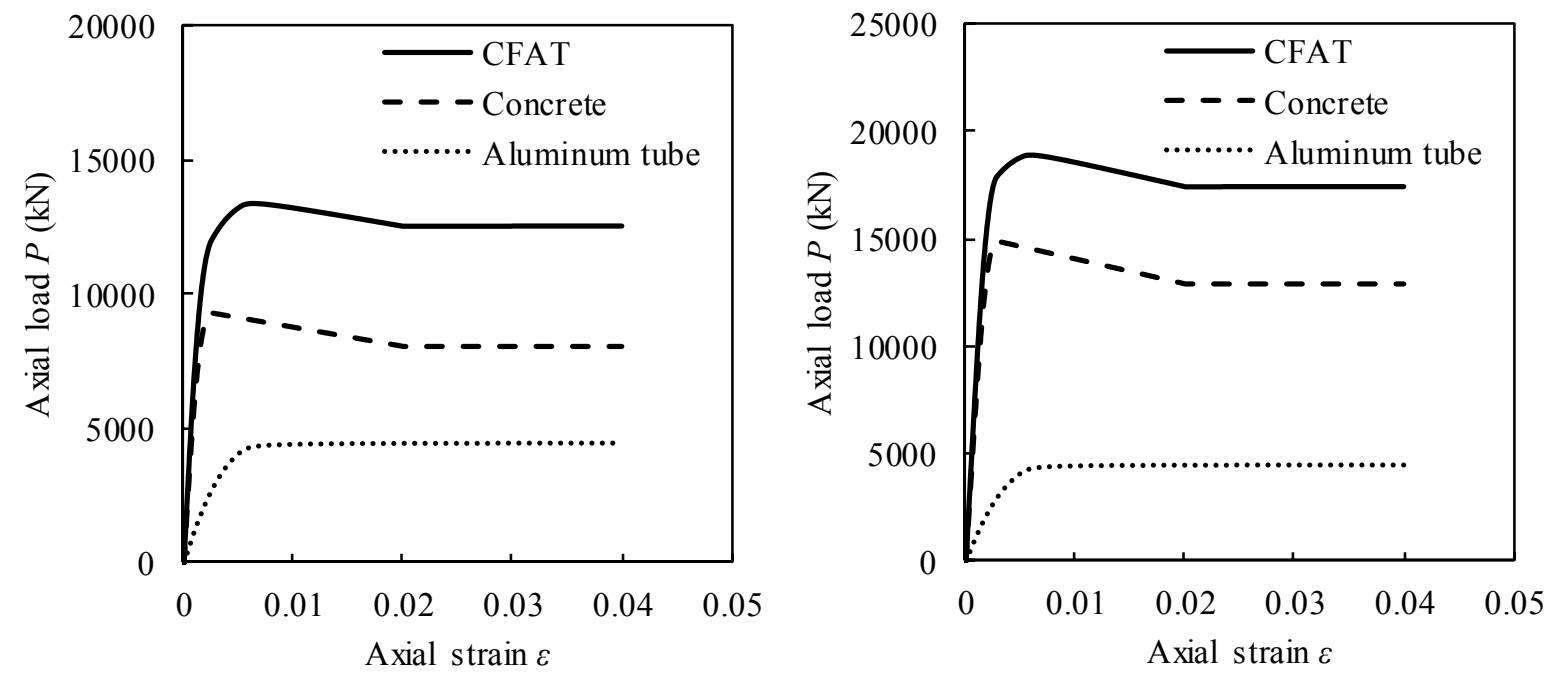

(a) $f_{c}^{\prime}=40 \mathrm{MPa}$

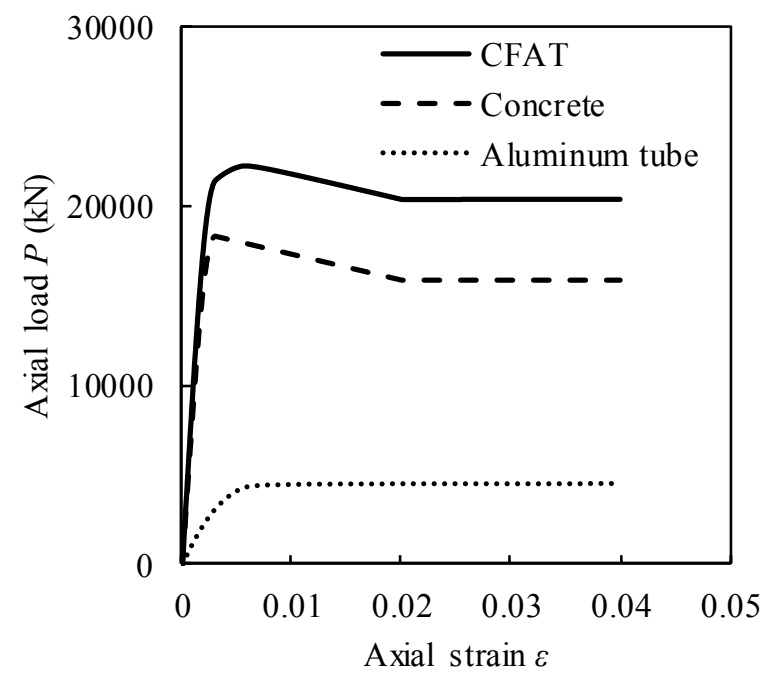

(b) $f_{c}^{\prime}=65 \mathrm{MPa}$

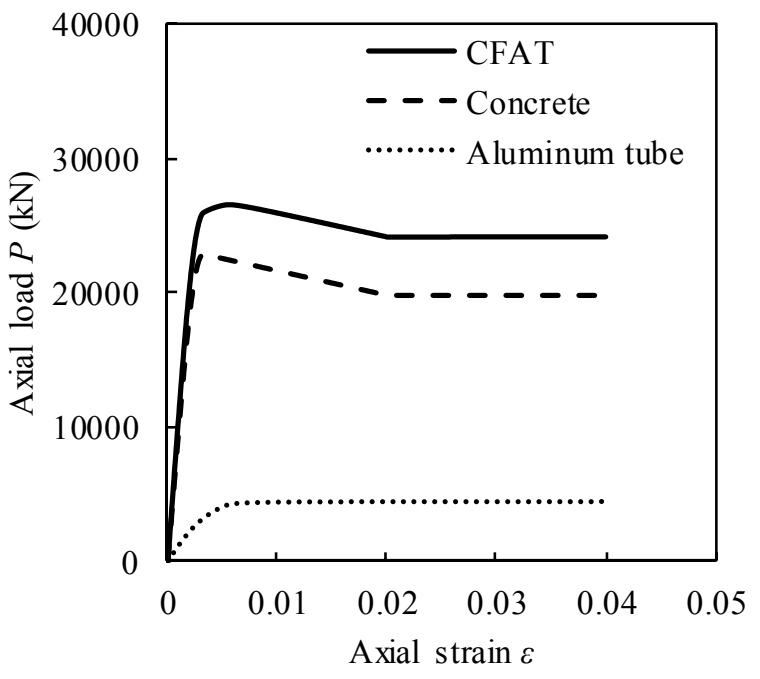

(c) $f_{c}^{\prime}=80 \mathrm{MPa}$

(d) $f_{c}^{\prime}=100 \mathrm{MPa}$

Fig. 13. Axial load distributions in circular CFAT short columns with various concrete strengths.

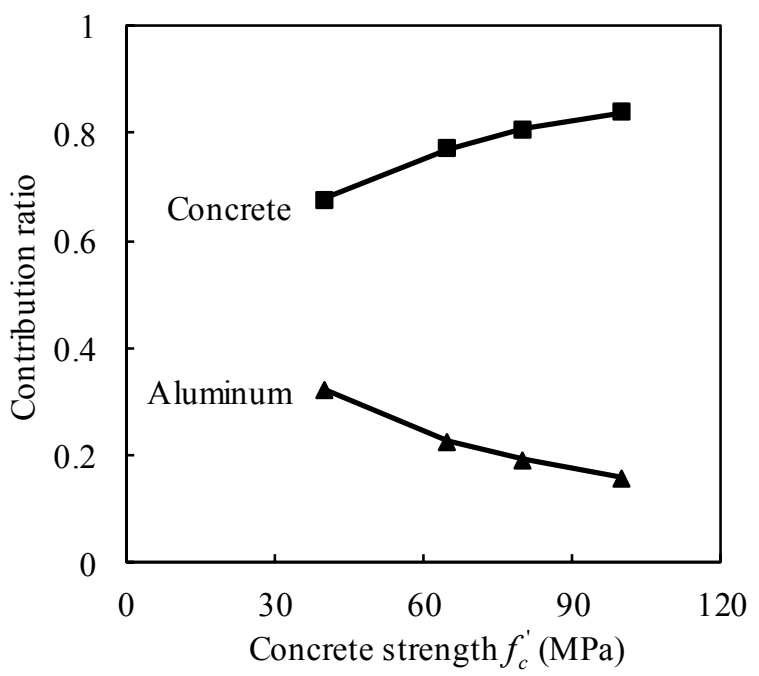


Patel, V. I., Liang, Q. Q. and Hadi, M. N. S. (2020). Numerical simulations of circular high strength concrete-filled aluminum tubular short columns incorporating new concrete confinement model. Thin-Walled Structures, 147: 106492.

Fig. 14. Effect of concrete strength on contribution ratios.

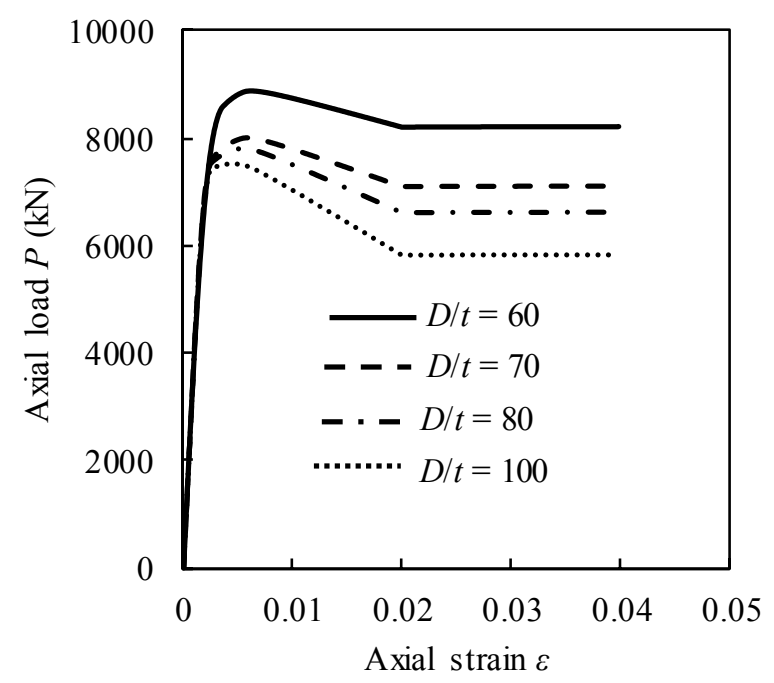

Fig. 15. Influence of $D / t$ ratio on axil load-strain curves.

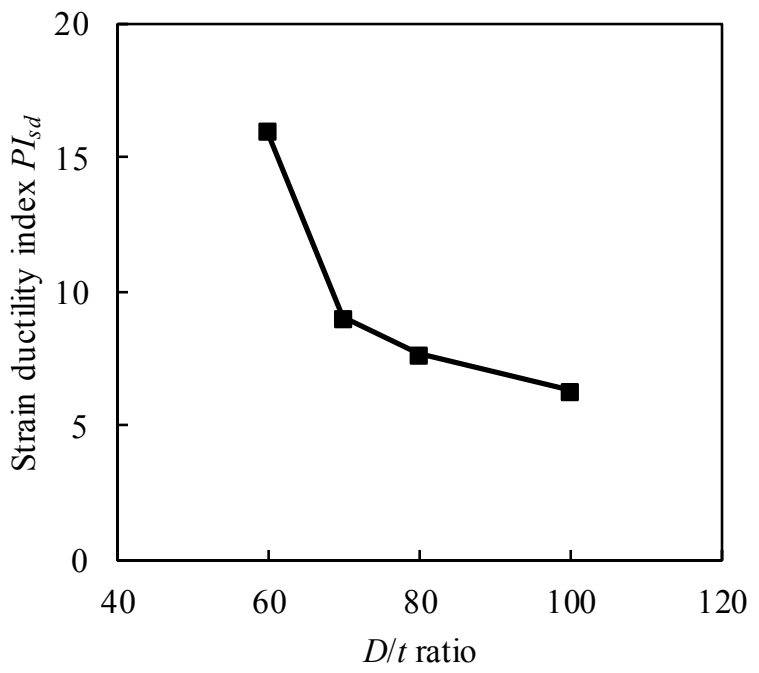


Patel, V. I., Liang, Q. Q. and Hadi, M. N. S. (2020). Numerical simulations of circular high strength concrete-filled aluminum tubular short columns incorporating new concrete confinement model. Thin-Walled Structures, 147: 106492.

Fig. 16. Influence of $D / t$ ratio on strain ductility index $P I_{s d}$.

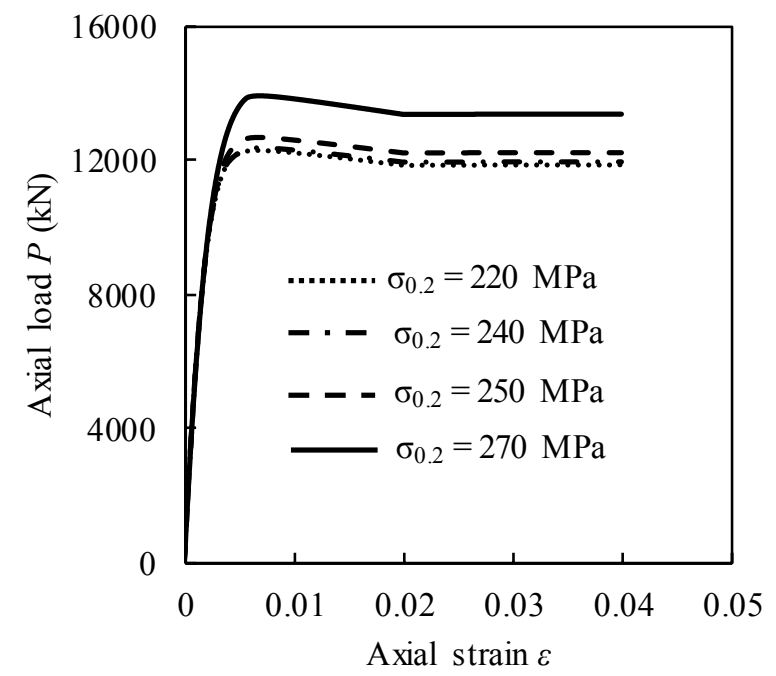

Fig. 17. Influence of aluminum proof stress $\sigma_{0.2}$ on axial load-strain responses.

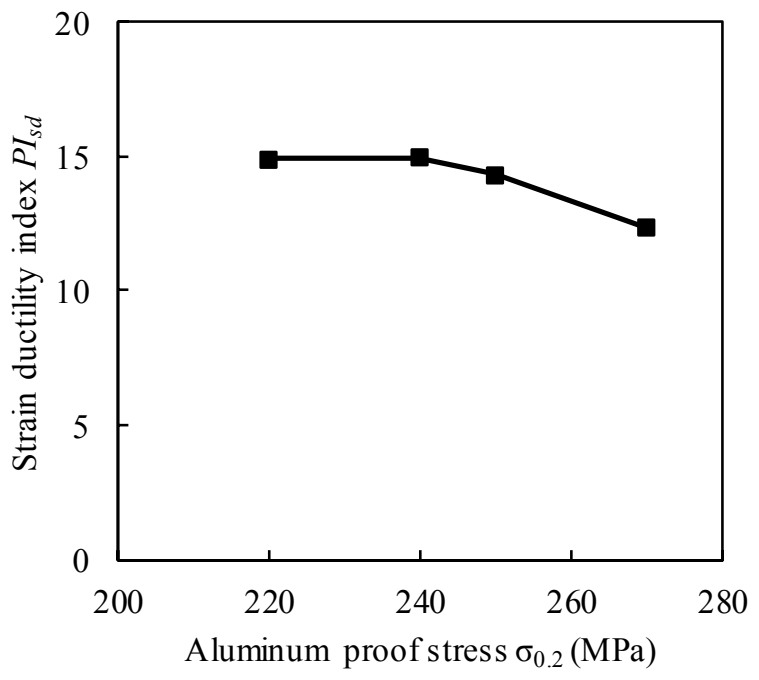


Patel, V. I., Liang, Q. Q. and Hadi, M. N. S. (2020). Numerical simulations of circular high strength concrete-filled aluminum tubular short columns incorporating new concrete confinement model. Thin-Walled Structures, 147: 106492.

Fig. 18. Effect of aluminum proof stress on strain ductility index.

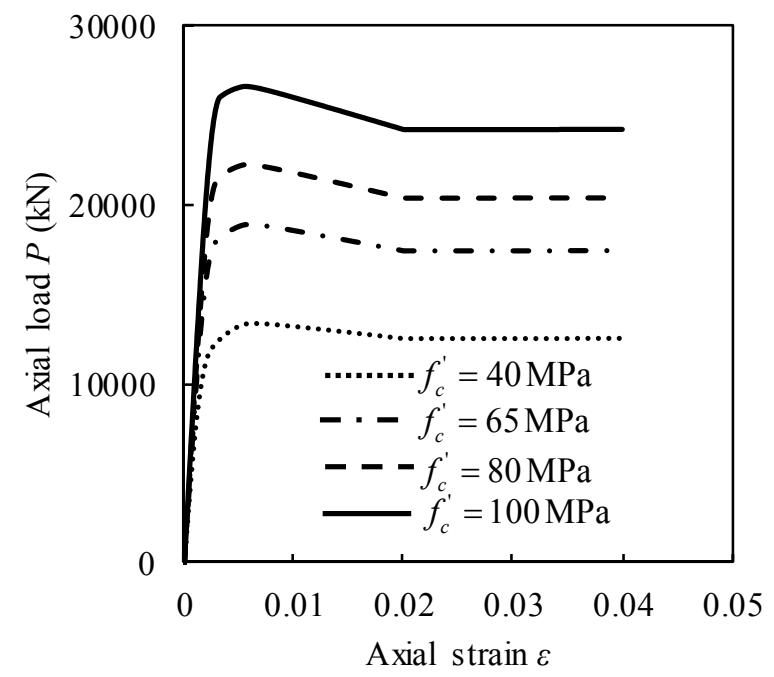

Fig. 19. Influence of concrete compressive strength on axial load-strain responses.

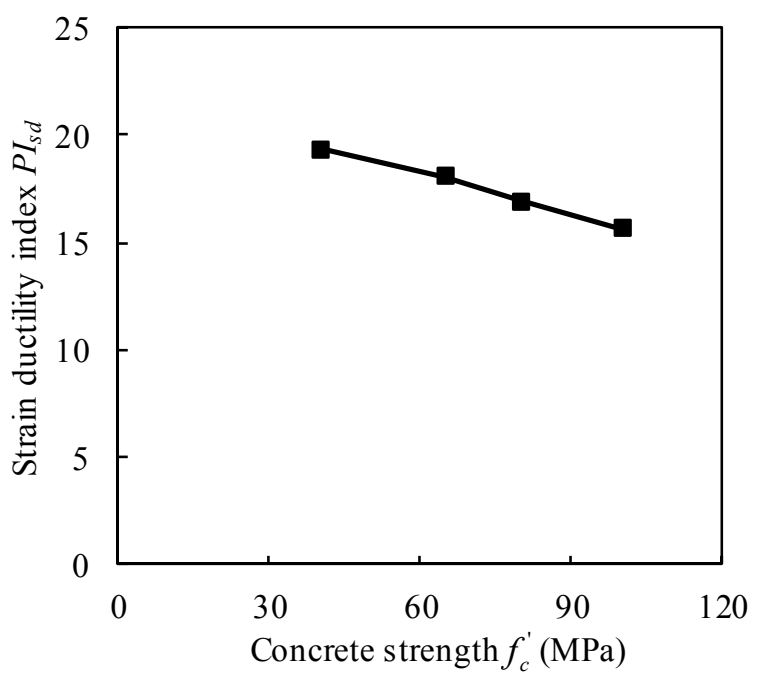

Fig. 20. Influence of concrete compressive strength $f_{c}^{\prime}$ on strain ductility index $P I_{s d}$. 
Patel, V. I., Liang, Q. Q. and Hadi, M. N. S. (2020). Numerical simulations of circular high strength concrete-filled aluminum tubular short columns incorporating new concrete confinement model. Thin-Walled Structures, 147: 106492.

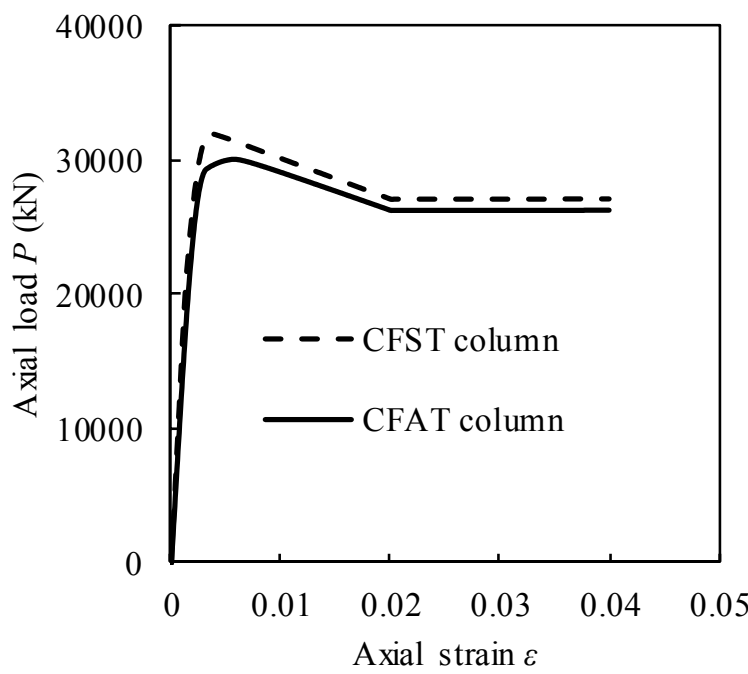

Fig. 21. Comparison of axial load-strain responses of circular CFST and CFAT columns. 